\title{
Oral administration of iron-saturated bovine lactoferrin-loaded ceramic nanocapsules for breast cancer therapy and influence on iron and calcium metabolism
}

\author{
This article was published in the following Dove Press journal: \\ International Journal of Nanomedicine \\ 22 June 2015 \\ Number of times this article has been viewed
}

\section{Ganesh Mahidhara \\ Rupinder K Kanwar \\ Kislay Roy \\ Jagat R Kanwar}

Nanomedicine-Laboratory of Immunology and Molecular Biomedical Research, School of Medicine, Molecular and Medical Research Strategic Research Centre, Faculty of Health, Deakin University, Waurn Ponds, VIC, Australia
Correspondence: Jagat R Kanwar Nanomedicine-Laboratory of Immunology and Molecular Biomedical Research, School of Medicine, Molecular and Medical Research Strategic Research Centre, Faculty of Health, Deakin University, Locked Bag 20000, Geelong, VIC 3220, Australia

Tel +6I 35227 | | 48

Fax+6I 352273402

Email jagat.kanwar@deakin.edu.au
Abstract: We determined the anticancer efficacy and internalization mechanism of our polymeric-ceramic nanoparticle system (calcium phosphate nanocores, enclosed in biodegradable polymers chitosan and alginate nanocapsules/nanocarriers [ACSC NCs]) loaded with iron-saturated bovine lactoferrin (Fe-bLf) in a breast cancer xenograft model. ACSC-Fe-bLf $\mathrm{NCs}$ with an overall size of $322 \pm 27.2 \mathrm{~nm}$ were synthesized. In vitro internalization and anticancer efficacy were evaluated in the MDA-MB-231 cells using multicellular tumor spheroids, CyQUANT and MTT assays. These NCs were orally delivered in a breast cancer xenograft mice model, and their internalization, cytotoxicity, biodistribution, and anticancer efficacy were evaluated. Chitosan-coated calcium phosphate Fe-bLf NCs effectively $(59 \%, P \leq 0.005)$ internalized in a 1-hour period using clathrin-mediated endocytosis $(P \leq 0.05)$ and energy-mediated pathways $(P \leq 0.05$ ) for internalization; $3.3 \mathrm{mg} / \mathrm{mL}$ of ACSC-Fe-bLf NCs completely disintegrated $(\sim 130$-fold reduction, $P \leq 0.0005)$ the tumor spheroids in 72 hours and 96 hours. The $\mathrm{IC}_{50}$ values determined for ACSC-Fe-bLf NCs were $1.69 \mathrm{mg} / \mathrm{mL}$ at 10 hours and $1.62 \mathrm{mg} / \mathrm{mL}$ after 20 hours. We found that Fe-bLf-NCs effectively $(P \leq 0.05)$ decreased the tumor size (4.8-fold) compared to the void NCs diet and prevented tumor recurrence when compared to intraperitoneal injection of Taxol and Doxorubicin. Receptor gene expression and micro-RNA analysis confirmed upregulation of low-density lipoprotein receptor and transferrin receptor (liver, intestine, and brain). Several micro-RNAs responsible for iron metabolism upregulated with NCs were identified. Taken together, orally delivered Fe-bLf NCs offer enhanced antitumor activity in breast cancer by internalizing via low-density lipoprotein receptor and transferrin receptor and regulating the micro-RNA expression. These NCs also restored the body iron and calcium levels and increased the hematologic counts.

Keywords: oral delivery, Fe-bLf, miRNA, xenograft, breast cancer

\section{Introduction}

Breastcancerneoplasms are the leading cause of death by cancer, among women in the world. More than half of the new cases of breast cancer occur in developed countries in comparison to the total number of incidents diagnosed worldwide. ${ }^{1,2}$ The chemotherapy offered involves a number of side effects during the course or after the completion of the treatment such as neuropathy, fatigue, leukemia, and cognitive dysfunction. ${ }^{3,4}$ Chemotherapeutics are also reported to impose severe problems like congestive heart failure, ventricular tachycardia, and sudden death. ${ }^{5}$ Alternative natural anticancer remedies have gained high patient compliance. It is established that milk and colostrum are a rich source of potential health-enhancing proteins, and bovine lactoferrin (bLf) in particular has been 
well characterized for its antibacterial, antifungal, antiviral, antiparasitic, and anticancer activities. ${ }^{6} \mathrm{We}$ have previously established that iron saturation increases the anticancer efficacy of bLf and that orally fed iron-saturated bLf (FebLf) augmented anticancer chemotherapy ${ }^{7}$ and has already established its anticancer activity in different cancer models. ${ }^{8}$ Lactoferrin also replenishes the body iron content to cure iron deficiency and increases RBC count and hemoglobin levels, thereby boosting the body immune system to fight back against chronic diseases. ${ }^{8}$

We have also shown that calcium phosphate nanocapsules/ nanocarriers (NCs) restore the body calcium concentration, which is highly essential for well-being. ${ }^{8}$ Apart from this, most of the anticancer synthetic drugs induce drug resistance; however, NCs do not produce drug resistance and have a longterm effect on treatment and prevention of cancer. ${ }^{9}$

In vivo enhancement of apoptosis and antiangiogenic activities creates the possibility of new objectives in order to carry further studies related to the intense molecular mechanisms in various other cancer types, such as breast cancer. This is the first and novel approach as an anticancer nanoneutraceutical for breast cancer therapy with natural protein that targets not only cancer cells but also cancer stem cells. ${ }^{9}$ However, the main aim of this study was to test the antitumor efficacy of alginate-enclosed chitosan-calcium phosphate (ACSC)-Fe-bLf NCs in vitro and in vivo in xenograft breast cancer model. Furthermore, using immunohistochemical data, real-time polymerase chain reaction (RT-PCR), and micro-RNA (miRNA) analysis, internalization mechanism of the Fe-bLf-loaded NCs was evaluated in a breast cancer xenograft model of nude (C57BalbC nu/nu) mice.

\section{Materials and methods Materials}

Low-molecular weight chitosan with a $20 \mathrm{cp}$ to $200 \mathrm{cp}$ viscosity, average molecular weight of $200 \mathrm{kDa}$ and deacetylation degree of $80 \%$, sodium tripolyphosphate, sodium alginate, potassium bromide pellets, horseradish peroxidase-conjugated anti-goat antibody, and actin antibody were purchased from Sigma-Aldrich (Castle Hill, NSW, Australia). Formvar with carbon coating on 100 mesh for transmission electron microscopy (TEM) analysis was from ProSciTech (Kirwan, QLD, Australia). TACS ${ }^{\circledR}$ MTT (3-(4,5Dimethylthiazol-2-yl)-2,5-Diphenyltetrazolium Bromide) cell proliferation assay kit was purchased from Trevigen (Bio Scientific, Pty. Ltd, Kirrawee, NSW, Australia). MDAMB-231 cell lines were obtained from ATCC (Manassas, VA, USA). Polyvinylidene fluoride membranes for Western blotting were from Amersham Biosciences (Castle Hill, NSW, Australia). Casein-free animal diet (AIN93G rodent diet) was purchased from Specialty Feeds (Glen Forrest, WA, USA). Hematoxylin, eosin, and other immunohistochemical reagents were from Lomb Scientific (Scoresby, VIC, Australia). Lissamine rhodamine, superscript III for reverse transcription was from Invitrogen Life Technologies (Mulgrave, VIC, Australia). SYBR green super mix for quantitative RT-PCR (qRT-PCR) was from Bio-Rad (Gladesville, NSW, Australia).

\section{Cell culture and conditions}

Human breast cancer (MDA-MB-231) cells were grown as a monolayer in the Leibovitz (L-15) media supplemented with $10 \%$ heat-inactivated fetal bovine serum, penicillin (20 units $/ \mathrm{mL})$, and streptomycin $(20 \mathrm{mg} / \mathrm{mL})$ at $37^{\circ} \mathrm{C}$ in a saturated humid atmosphere without $\mathrm{CO}_{2}$. After reaching $80 \%-90 \%$ confluency in the culture flasks, cells were harvested by a brief ( $5 \mathrm{~min}$ ) trypsinization. For cytotoxicity assessment, cells were seeded onto 96-well tissue culture plates at concentrations of $1 \times 10^{3}$ cells/well. For RNA isolation, cells were seeded onto 6 - or 12 -well tissue culture plates at a concentration of $1 \times 10^{6}$ cells/well.

\section{Saturation of bLf with iron}

Iron saturation of APO form (iron-free form) of bLf was done using Fe (III) coordinate complexes using a previously published methodology. ${ }^{7}$ Briefly, native bovine Lf, after treatment with mild acidic solution ( $\mathrm{pH}$ 2.6) was dialyzed for a period of 48 hours in $0.1 \mathrm{M}$ citric acid to get rid of the bound metal ions and then saturated with ferric [Fe(III)] nonahydrate for 2 hours with stirring to form $\mathrm{Lf}-\mathrm{Fe}^{3+}$ coordinate complexes for the development of deep-red-colored Fe-bLf. The resultant complex was also dialyzed for a period of 48 hours to remove the unbound $\mathrm{Fe}$. The obtained Fe-bLf was loaded on to the chitosan-coated calcium phosphate (CSC) NCs and covered with alginate (ACSC NCs) to test its size and effect against cancer cells.

\section{Preparation of ACSC-Fe-bLf NCs}

We have reported the synthesis of alginate-enclosed chitosancoated ceramic NCs encapsulated with Fe-bLf in our previous studies. ${ }^{8}$ The same procedure was used to prepare the NCs in the present study. Briefly, $1 \% \mathrm{w} / \mathrm{v}$ calcium phosphate was incubated for 24 hours with 10\% w/w Fe-bLf with constant stirring at $4^{\circ} \mathrm{C}$. After adding $0.01 \% \mathrm{w} / \mathrm{w}$ chitosan (acetate buffer, $\mathrm{pH} 4$ ), $0.01 \%$ sodium tripolyphosphate was added dropwise for cross-linking. Stirring at 6,000 rpm for 12 hours 
was done to ensure that the nano-formulation obtained a size of $205 \pm 15 \mathrm{~nm}$. Alginate solution ( $2 \% \mathrm{w} / \mathrm{v})$ and calcium chloride, with $0.6 \%$ mass ratio of $\mathrm{Ca}$ /alginate, were added. The finally obtained NCs were washed and lyophilized for further experimentation. All the experiments were performed at $4{ }^{\circ} \mathrm{C}$ so as to protect the polymer and protein components in the nano-formulation.

\section{Determination of physical parameters for ACSC-Fe-bLf NCs}

In order to characterize the synthesized NCs, it was important to determine their physical parameters. Dynamic light scattering was used to determine the sizes of calcium phosphate-FebLf, calcium phosphate-chitosan-Fe-bLf(CSC-Fe-bLf), and alginate-encapsulated calcium phosphate-chitosan-Fe-bLf (ACSC-Fe-bLf) with the help of zetasizer (Malvern Zetasizer Nano-ZS). The number of particles per milligram per milliliter was also determined using the option number particle size index in the zetasizer. Surface morphology of these particles was determined by TEM (Jeol) at an accelerating voltage of $100 \mathrm{kV}$. Samples for TEM were fixed on carbon mesh (Formvar with carbon coating on 100 mesh) and dyed with ruthenium tetroxide in order to visualize in the accelerating electric field at 50,000× magnification. Scanning electron microscopy (Supra, Zeiss) was performed to determine the shape and size of ACSC-Fe-bLf nanoparticles. The sample was coated with gold coating using SCD 050 sputter coater (Leica Microsystems, Wetzlar, Germany) and observed at an extra high tension of 10 and a working distance of 6-12 $\mathrm{mm}$. The physicochemical characterization was performed using Fourier transform infrared spectroscopy with a Bruker Vertex-70 Fourier transform infrared spectroscope. In vitro release profile of the protein was carried out in varying $\mathrm{pH}(1.5,2$, and 8$)$. ACSC NC (1\% w/v) was suspended into phosphate buffered saline (PBS) at varying $\mathrm{pH}$ under constant stirring and maintained at a temperature of $37^{\circ} \mathrm{C}$. The sample was centrifuged and dispersed in fresh solution, and the supernatants were analyzed for protein concentration (Bradford coomassie method) at various time intervals, starting from 1 hour till 96 hours. Calorimetric measurements were carried out using differential scanning calorimetry (DSC-204, Netzsch) with a standard crucible covered with a lid, but not sealed, in an atmosphere of dry nitrogen. Each sample (3-5 mg) was heated in an aluminum pan from $25^{\circ} \mathrm{C}$ to $700^{\circ} \mathrm{C}$ at a flow rate of $10^{\circ} \mathrm{C} / \mathrm{min}$ under dry nitrogen. Thermogravimetric analysis (TGA) was also carried out to determine the thermal and oxidative stabilities of the NCs. The effect of varying the $\mathrm{pH}(2-8)$ was also tested on the stability and the size of these NCs using sodium dodecyl sulfate-polyacrylamide gel electrophoresis and dynamic light scattering.

The encapsulation efficiency of the particles was determined using the following formula: ${ }^{10}$

$$
\% \mathrm{EE}=\frac{\text { Total protein }- \text { free protein insupernatant }}{\text { Total protein }} \times 100
$$

The loading capacity of the particles was determined using the following formula: ${ }^{11}$

$$
\% \mathrm{LC}=\frac{\text { Total protein }- \text { free protein in supernatant }}{\text { nanoparticle weight }(\mathrm{mg})} \times 100
$$

\section{Rhodamine labeling procedure}

ACSC-Fe-bLf NCs were freeze dried and incubated in $0.01 \%$ rhodamine (Sigma-Aldrich) solution under constant spinning at low speed for 24 hours. The NC suspension was centrifuged at $2,000 \mathrm{rpm}$ for 5 minutes at $4^{\circ} \mathrm{C}$. The supernatant was discarded, and the NC pellet was washed with PBS to remove the unbound rhodamine. Therefore, the rhodamine was not chemically linked, but adsorbed on the surface of the NCs as observed in previously published protocols. ${ }^{8,9}$

\section{ACSC NCs uptake mechanism}

In order to study the NCs uptake, MDA-MB-231 were treated with $1 \mathrm{mg} / \mathrm{mL}$ of $0.01 \%$ rhodamine-labeled CSC-Fe-bLf NCs for 1-hour, 4-hour, 6-hour, and 12-hour periods. Posttreatment the cells were fixed using $4 \%$ paraformaldehyde and 4',6-diamidino-2-phenylindole was added, and the slides were viewed using Leica TCS sp5 confocal microscope. Flow cytometric analysis was also performed to study the uptake mechanism using flow cytometric analysis in $\mathrm{BD}^{\circledR} \mathrm{FACS}$ Canto II. In order to determine the mechanism of entry of NCs in cells, MDA-MB-231 cells were pretreated with the following endocytic inhibitors: chlorpromazine $10 \mu \mathrm{g} / \mathrm{mL}$ (clathrin-mediated endocytosis), indomethacin $10 \mu \mathrm{g} / \mathrm{mL}$ (caveola-mediated endocytosis), sodium azide $2 \mu \mathrm{g} / \mathrm{mL}$, and colchicine $5 \mu \mathrm{g} / \mathrm{mL}$ (pinocytosis), and antibodies to transferrin receptors (TfR) and low-density lipoprotein receptor (LRP) for 1 hour followed by incubation with rhodamine-labeled ACSC-Fe-bLf NCs for 4 hours at a concentration of $1 \mathrm{mg} / \mathrm{mL}$. ${ }^{9,12,13}$ Posttreatment cell lysates were obtained, and fluorescence was measured at $530 \mathrm{~nm}$ excitation and $630 \mathrm{~nm}$ emission, and the corresponding weight of the ACSC NCs was calculated from the standard graph plotted for rhodamine-labeled ACSC NCs. 


\section{In vitro anticancer efficacy of NCs}

Agarose solution (100 $\mu \mathrm{L}$ at $0.1 \%)$ was added in 96-well plates. Once agar was solidified, MDA-MB-231 cells in a concentration of $1 \times 10^{3}$ cells per well were added. Cells were incubated for 7 days at $37^{\circ} \mathrm{C}$ with $5 \% \mathrm{CO}_{2}$, and they formed uniform spheroids in all the wells. ${ }^{14}$ The spheroids were further treated with ACSC-Fe-bLf NCs $\left(9.01 \times 10^{5}\right)$ corresponding to $3.3 \mathrm{mg} / \mathrm{mL}$ of Fe-bLf and nano-free Fe-bLf protein $(3.3 \mathrm{mg} / \mathrm{mL})$ up to 96 hours. The CyQUANT cell proliferation assay kit was used to assess cellular proliferation of breast cancer cells after the treatment with NCs. Different formulations of NCs (void, ACSC-Fe-bLf, and CSC-FebLf) were used to treat the cells in order to observe the cell viability. After 20 hours incubations. Cell viability analysis of MDA-MB-231 cells was determined using TACS-MTT assay kit as per the manufacturer's instructions. The $\mathrm{IC}_{50}$ values were determined by the equation derived from respective logarithmic curves (Figures S1 and S2).

\section{Preparation of diet containing ACSC-Fe- bLf NCs for oral therapy in vivo}

The dose of Fe-bLf was standardized as in our previous studies, where we reported that $1.2 \%(\mathrm{w} / \mathrm{w})$ or $12 \mathrm{~g}$ of Fe-bLf $/ \mathrm{kg}$ diet prevented the tumor development. ${ }^{7}$ The same dose of Fe-bLf was also used in the nanoformulated diet with similar findings. ${ }^{8,9}$ The diet was checked for compatibility and stability of the NCs. The amount of nano-diet consumed by each mouse daily was also calculated. ${ }^{9}$

\section{Induction of tumor and in vivo studies}

In vivo studies were conducted in athymic nude mice (C57BL nu/nu, 6-8 weeks of age) subcutaneously injected with $1 \times 10^{6}$ MDA-MB-231 (into the fat pad) cancer cells following the guidelines by the Animal Ethics Committee, Geelong, Deakin University. In preventive study, mice were fed two types of diet, control (no Fe-bLf NCs) diet and ACSC-Fe-bLf NC diet, which was further divided into two groups, where ACSCFe-bLf group 1 received oral diet of ACSC-Fe-bLf NCs till the end of the experiment ( 65 days) and the diet was switched to normal diet upon second challenge in the case of ACSC-Fe-bLf group 2 (45th day). In this study, the first challenge referred to tumor cell injection. In the case of control group, once the tumor reached $200 \mathrm{~mm}^{3}$ in volume, intraperitoneal injection of Taxol was given. Second challenge was done on both control as well as treatment groups with $1 \times 10^{7}$ MDA-MB-231 cells. The second challenge refers to the reinjection of tumor cells, which was performed to mimic the situation of tumor recurrence. Whereas, in the case of treatment studies, mice were fed on three types of diet: control diet, ACSC-Fe-bLf NCs diet, and control diet void NCs (without the protein). Another group of mice received an intraperitoneal injection of Taxol + Doxorubicin as a chemotherapeutic control. Body weight, behavioral changes, and tumor sizes were observed at regular intervals of 5 days each. Tumor growth was determined by measuring two perpendicular diameters, as described previously. ${ }^{15,16}$ In accordance with Animal Ethics Committee Geelong (AECG), animals were humanely killed once the tumors reached $1.0 \mathrm{~cm}$ in diameter. After completion of the treatment period, different groups of mice were sacrificed, and the tissues were harvested, snap frozen, and stored at $-80^{\circ} \mathrm{C}$ until further use.

\section{Tissue processing and hematoxylin and eosin staining}

All the tissues were washed with PBS to remove all hysteresis. Intestinal sections especially were washed from the interior (lumen) to clear any feces. The sections were fixed using 4\% paraformaldehyde, frozen in optimum cutting temperature compound, and stored at $-20^{\circ} \mathrm{C}$ and sectioned in cryotome as $5 \mu \mathrm{m}$-thin sections. The cryotomic sections, which were placed on a glass slide, were fixed using ice-cold acetone solution (1:1 mixture of acetone and distilled water). The sections were rehydrated in distilled water and stained with hematoxylin and eosin using routine sectioning and staining techniques.

\section{Immunohistochemistry}

For immunohistochemical staining, the sections were fixed and rinsed in distilled water to remove the OCT compound. The sections were rehydrated with tris buffer saline-tween-20 and blocked with $3 \%$ hydrogen peroxide in $0.3 \%$ rabbit serum to overcome endogenous peroxidase activity. Goat antibovine Lf antibody (Bethyl Labs, USA) $(1: 1,000)$ was used for the detection of exogenous Fe-bLf with anti-goat horseradish peroxidase-conjugated IgG secondary antibody. The sections were then washed in TBS-T and developed with DAB (3,3'-Diaminobenzidine) substrate (Sigma-Aldrich) and incubated for 10 minutes in dark. After counterstaining with hematoxylin, slides were fixed with permanent mounting media and observed under $100 \times$ oil immersion objective using a bright-field microscope (Zeiss Axioscope 2plus).

\section{CD3I and Prussian blue double staining}

To determine angiogenic vasculature in the tissue of interest, $10 \mu \mathrm{m}$ frozen sections were immunostained with goat anti-CD31 antibody and probed. CD31-positive blood vessels were detected using anti-goat IgG secondary antibody. Further, to develop Prussian blue staining and to visualize the iron reactivity, tissues were incubated 
for 20 minutes with Prussian blue stain and the slides were counterstained with neutral red stain for 1 minute. After serial dehydration in gradients of ethanol, the slides were fixed with permanent mounting media and observed under the microscope for Prussian blue and CD31 double staining.

\section{qRT-PCR analysis}

The role of LRP and TfR in translocation of Fe-bLf was analyzed using a previously mentioned procedure. ${ }^{17}$ RNA extraction was carried out by the TRizol method (Invitrogen Inc, USA) as per the manufacturer's instructions, and purified RNA was confirmed by $1 \%$ agarose electrophoresis. Obtained RNA was converted to cDNA by SuperScript ${ }^{\circledR}$ III First-Strand Synthesis System (Invitrogen Inc, USA) as per the manufacturer's protocol. qRT-PCR analysis of the receptor genes (Table S1) was carried out by qRT-PCR system (Biorad Inc, USA).

\section{Regulation of miRNAs involved in iron metabolism by alginate enclosed chitosan coated-calcium phosphate-Fe-bLf NCs}

The cDNA was generated from $2 \mu \mathrm{g}$ of RNA using TaqMan ${ }^{\circledR}$ MicroRNA Reverse Transcription Kit (Applied Biosystems) according to the manufacturer's protocol. The miRNAs gene-specific stem-loop RT primer for reverse transcription was designed according to miRNAs sequences listed in the Sanger miRBase (http://microrna.sanger.ac.uk/sequences/) (Applied Biosystems).

\section{Blood collection and analysis}

Whole blood for complete blood count was collected from the retro-orbital plexus into EDTA-treated microtainer tubes (Becton Dickinson, Franklin Lakes, NJ, USA) from mice under Avertin (Sigma, St Louis, MO, USA) anesthesia and analyzed on an ADVIA 120 analyzer (Bayer, Tarrytown, NY). Blood smears were stained with Wright-Giemsa stain (Fisher Diagnostics, Middletown, VA, USA) according to the manufacturer's directions. Iron, calcium, and zinc in the serum (Supplementary materials) were measured as described in our previous studies. ${ }^{8,9}$

\section{Statistical analysis}

All values were expressed as mean \pm standard deviation obtained from at least three experiments unless otherwise stated. For the statistical evaluation of numerical data, one-way analysis of variance with Duncan's variance (SPSS 15) was used to compare the groups. $P$-values $\leq 0.05$ were considered significant.

\section{Results and discussion}

\section{Formulation, development, and} physicochemical characterization of NCs

We aimed to develop a nanoformulated neutraceutical controlled-release oral therapy for breast cancer. Calcium phosphate is known to have excellent biocompatibility, ${ }^{18}$ and chitosan has potential health benefits and is a mucoadhesive polymer. ${ }^{19}$ Sodium alginate was declared generally regarded as safe for oral administration/consumption by the US Food and Drug Administration in $1973 .{ }^{20}$ Therefore, this NC has three components: calcium phosphate-Fe-bLf nanocore, further coated with chitosan and Fe-bLf to form CSC NCs. The CSC NCs are coated with alginate to form ACSC NCs. The alginate coating is done to preserve the Fe-bLf from acidic environment in stomach because the un-ionized form of alginate does allow the protein to diffuse only in a slow rate in case of lower $\mathrm{pH} .{ }^{21}$ When in the intestine, the alginate layer is shed off to expose the final form of NCs, which is CSC NCs that are absorbed by the intestinal cells. ${ }^{8,9}$ On the calcium phosphate ceramic nanocore, $100 \%$ iron-saturated Fe-bLf was loaded followed by chitosan and alginate (Figure 1A). ${ }^{22}$ TEM (Figure 1B) and scanning electron microscopy images (Figure 1C) showed spherical size and particle size range of 300-350 nm. An average size of $205 \pm 15 \mathrm{~nm}$ for CSC inner core was observed, which was increased to $322 \pm 27.2 \mathrm{~nm}$ after enclosing with alginate to be able to form a final ACSC-Fe-bLf NC (Figure 1D). The zeta potential for the NCs was found to be $-1.29 \mathrm{mV}$ due to the outer coating of alginate. A total of $4.85 \times 10^{4} \mathrm{NCs}$ in $1 \% \mathrm{w} / \mathrm{V}$ suspension was observed during the analysis for the total number of NCs per milliliter of suspension. It was found that $0.17 \mathrm{mg}$ of Fe-bLf was present in $1 \mathrm{mg}$ of $\mathrm{NCs}$; therefore, $3.57 \mathrm{ng}$ of Fe-bLf was calculated to be present on each NC. The encapsulation efficiency of the NCs was found to be $80 \%$ and the loading capacity of the NCs was found to be $25.8 \%$ (Table 1). Controlled-release profiles of Fe-bLf from ACSC-Fe showed an initial burst at the end of 12 hours and a sustained release up to 96 hours, in a buffer in alkaline $\mathrm{pH}(\mathrm{pH}$ 8) (Figure 1E). However, release of the protein was minimal in acidic $\mathrm{pH}$ ( $\mathrm{pH} 1.5$ and 2 ) as only $55 \%$ of the total protein was released by the end of 96 hours. Low release of the protein in the acidic $\mathrm{pH}$ is attributed to the $\mathrm{pH}$ sensitivity of the alginate gel. ${ }^{23}$ Alginate system maintains its structure without any visible changes in morphology, although $\mathrm{Ca}^{+2}$ ions do not contribute any more to stabilize the system, leading to an initial burst. The un-ionized form of alginate does allow the protein to diffuse only in a slow rate in case of lower $\mathrm{pH}^{21}$ 
A

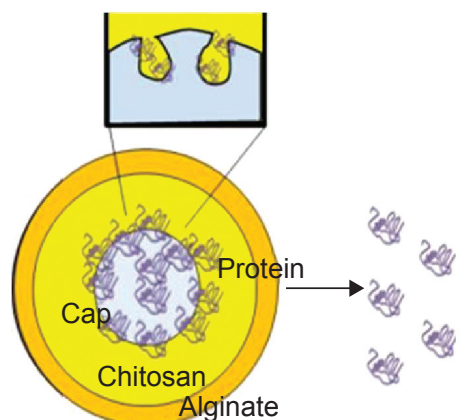

B

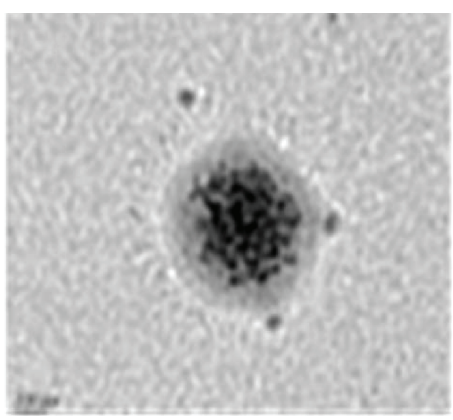

C

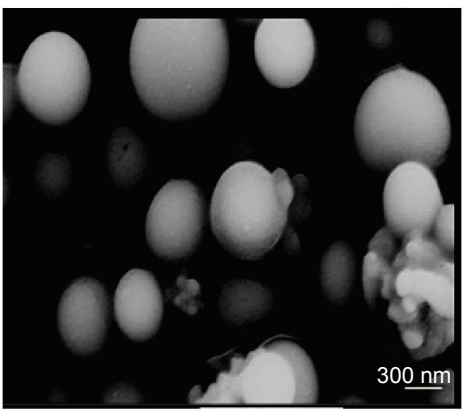

D

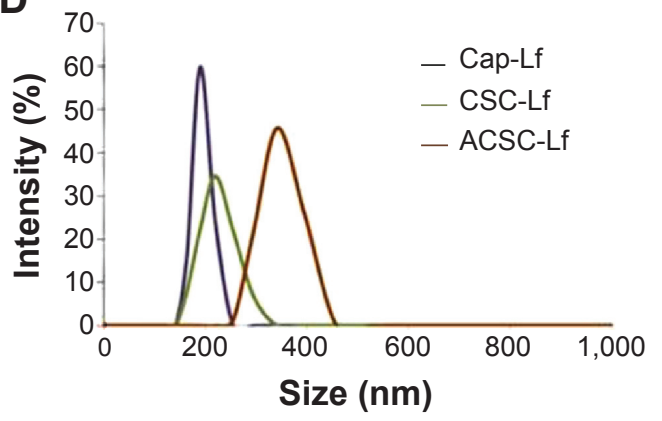

F

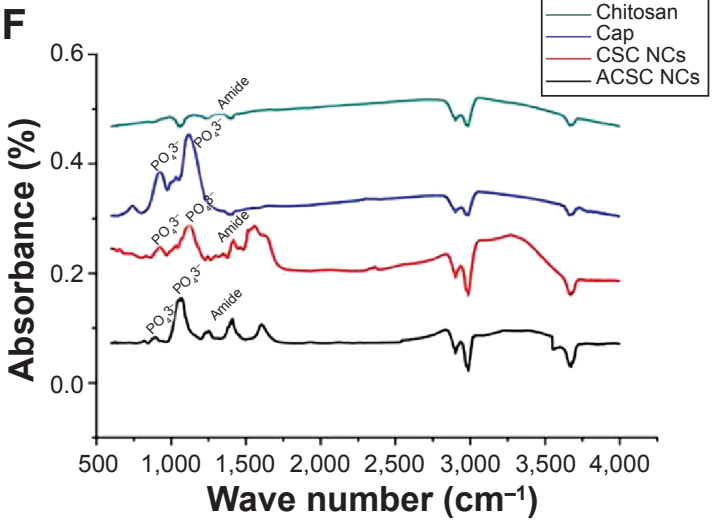

$\mathbf{E}$

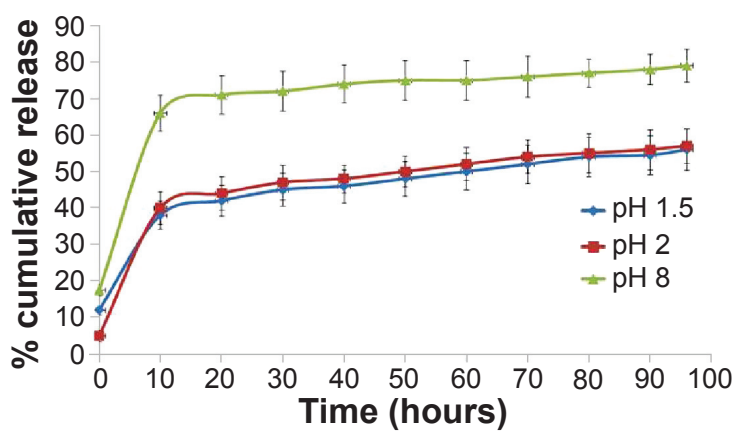

G

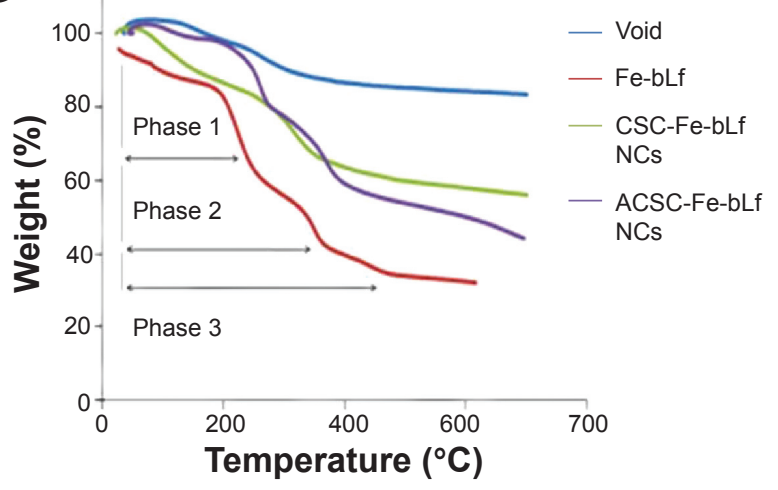

Figure I Formulation and physicochemical characterization of ceramic NCs.

Notes: (A) The ACSC-Fe-bLf NCs were found to have spherical morphology when observed under (B) transmission electron microscopy. Sphericity and size of ACSCFe-bLf NCs were reconfirmed by (C) scanning electron microscopy. (D) Size determination using dynamic light scattering spectrometry confirmed the size of $322 \pm 27.2 \mathrm{~nm}$ for ACSC-Fe-bLf NCs. (E) Controlled release of Fe-bLf from ACSC NCs as observed under $\mathrm{pH} \mathrm{I.5,} \mathrm{pH} 2$, and $\mathrm{pH} 8$ in a range of time starting from I hour to 96 hours. (F) The physicochemical characterization of the NCs was studied using Fourier transform infrared spectroscopy analysis. (G) Thermogravimetric analysis of NCs represented the arrangement of different layers to protect the encapsulated protein.

Abbreviations: ACSC, alginate-enclosed chitosan-coated calcium phosphate; Cap, calcium phosphate; CSC, chitosan-coated calcium phosphate; Fe-bLf, iron-saturated bovine lactoferrin; NCs, nanocapsules/nanocarriers.

Table I Comparison of physicochemical and biological characters in CSC-Fe-bLf NCs and ACSC-Fe-bLf NCs

\begin{tabular}{lll}
\hline Characteristics & CSC-Fe-bLf NCs & ACSC-Fe-bLf NCs \\
\hline Size, $\mathrm{nm}$ & $205 \pm 15$ & $322 \pm 27.2$ \\
Zeta potential, $\mathrm{mV}$ & -0.217 & -1.29 \\
Polydispersity index & 0.073 & 0.084 \\
Encapsulating efficacy & $80 \%$ & - \\
Loading capacity & $25.8 \%$ & - \\
$\mathrm{IC}_{50}$ at 20 hours & $1.192 \mathrm{mg} / \mathrm{mL}$ & $1.62 \mathrm{mg} / \mathrm{mL}$ \\
Internalization efficacy $\left(4 \times 10^{5} \mathrm{NCs}\right)$ & $86.6 \% \pm 2.25 \%$ & $43 \% \pm 1.5 \%$ \\
\hline
\end{tabular}

Abbreviations: ACSC, alginate-enclosed chitosan-coated calcium phosphate; CSC, chitosan-coated calcium phosphate; Fe-bLf, iron-saturated bovine lactoferrin; NCs, nanocapsules/nanocarriers. 
Fourier transform infrared spectra of chitosan, calcium phosphate, CSC NCs, and ACSC NCs were obtained and compared (Figure 1F). Characteristic peaks of free amide and $\mathrm{OH}$ groups corresponding to chitosan were observed in both CSC NCs as well as in pure chitosan. Amide group vibration can be seen at $1,340 \mathrm{~cm}^{-1}$ in case of chitosan. The characteristic peak for phosphate group in free calcium phosphate was observed at $924.4 \mathrm{~cm}^{-1}$ and $1,034 \mathrm{~cm}^{-1}$. A bridge peak corresponding to hydrogen bonding was observed in CSC NCs at $1,522 \mathrm{~cm}^{-1}$ proving the bonding of amino groups in the chitosan and phosphate group in the calcium phosphate. Furthermore, both phosphate and amino stretching vibrations were observed in ACSC NCs representing the ceramic core fit inside the alginate gel.

Three distinct regions of significant mass loss in the case of polymer-coated NCs were observed. A $10 \%$ mass loss was noticed between a temperature of $105^{\circ} \mathrm{C}$ and $247^{\circ} \mathrm{C}$ in ACSC NCs, followed by significant mass loss between the temperatures $265^{\circ} \mathrm{C}-330^{\circ} \mathrm{C}$ and $330^{\circ} \mathrm{C}-765^{\circ} \mathrm{C}$, indicating the presence of multiple polymeric layers in the nanocomposite (Figure 1G). Previously published studies have reported that a characteristic mass loss is observed in the TGA spectra of calcium phosphate nanoparticles at both $200^{\circ} \mathrm{C}$ and $400^{\circ} \mathrm{C}$ that corresponds to loss of adsorbed water and pyrophosphate formation. ${ }^{24}$ The TGA analysis of chitosan-sodium tripolyphosphate nanoparticles was performed in another study, and it was reported that the maximum loss of weight occurs at the temperature range of $225^{\circ} \mathrm{C}-530^{\circ} \mathrm{C} .{ }^{25}$ Meanwhile, studies have also reported that the maximum weight loss in TGA spectra of alginate is observed at $400^{\circ} \mathrm{C} .{ }^{26}$ Therefore, it could be inferred that the initial mass loss at $105^{\circ} \mathrm{C}$, and $247^{\circ} \mathrm{C}$ corresponded to that of calcium phosphate and the significant mass loss between the temperatures $265^{\circ} \mathrm{C}-330^{\circ} \mathrm{C}$, $330^{\circ} \mathrm{C}-765^{\circ} \mathrm{C}$, and $330^{\circ} \mathrm{C}-765^{\circ} \mathrm{C}$ corresponded to that of calcium phosphate, chitosan, and alginate.

\section{NC stability studies and in vitro assessment for internalization of ACSC- Fe-bLf NCs}

Differential scanning calorimetry thermograms of Fe-bLf protein, ACSC NCs loaded with protein, void NCs, and CSC NCs are shown in Figure 2A. Fe-bLf gives rise to a sharp peak at $272.17^{\circ} \mathrm{C}$, corresponding to the melting points of the crystalline regions. Void NCs show a small relaxation peak at $87.49^{\circ} \mathrm{C}$, whereas it was found at $91^{\circ} \mathrm{C}$ in the case of CSC NCs loaded with Fe-bLf. The same peak was shifted to $265^{\circ} \mathrm{C}$ in the case of ACSC NCs. Therefore, it could be inferred that the outer coating of chitosan and alginate had protective effects on the Fe-bLf. No notable melting point was observed in NCs as the polymers were amorphous. Moreover, the melting peaks of void and protein-loaded NCs were similar, indicating that the protein loading does not affect the polymer structure. In addition to this, characteristic peak of Fe-bLf was absent in the nanoformulation, indicating the conversion of crystalline protein to the amorphous form. The nanoparticle stability studies have been performed in our previous studies, ${ }^{9}$ where we have reported that the NCs are highly stable up to 90 weeks at $4^{\circ} \mathrm{C}-25^{\circ} \mathrm{C}$. The $\mathrm{NCs}$ showed little degradation at $\mathrm{pH} 2$ (Figure $2 \mathrm{~B}$ ), which was confirmed by dynamic light scattering. At $\mathrm{pH} 2$, only $15 \%$ of the NCs showed degradation while $85 \%$ NCs were intact with the size of $300-330 \mathrm{~nm}$. Therefore, this study indicated the stability of these NCs at acidic pH. However, at $\mathrm{pH} 8$ the size of NCs was lowered to $205 \mathrm{~nm}$ due to shedding of alginate layer (Figure 2C). These results confirm that an outer coating of alginate was able to protect the majority ( $85 \%$ ) of NCs from acidic degradation at $\mathrm{pH} 2$, which is used to mimic the physiological (acidic) environment within the stomach in mice. The key notion of using alginate layer is to protect the inner core from getting degraded in the gastrointestinal tract and alginate itself gets fragmented in the process, releasing the CSC inner core. Thus, the pool of CSC NCs will be abundant in a total population of NCs that have reached the final destination.

The images obtained from confocal microscope showed that the rhodamine-labeled CSC NCs $\left(4.5 \times 10^{5}\right.$ corresponding to $1.6 \mathrm{mg} / \mathrm{mL}$ ) successfully internalized in MDA-MB-231 cells within 1 hour. The nanoparticles were specifically attached to the cells, and there was an increase in their uptake with respect to time (Figure 2D). Flow cytometric analysis (Figure S3) showed an increase in cellular uptake of void CSC NCs from $21.8 \% \pm 0.5 \%$ in 1 hour to $59.8 \% \pm 0.9 \%$ in 12 hours, whereas the increase was observed to be prominent in $\mathrm{Fe}$ bLf-loaded CSC NCs from $62.5 \% \pm 0.3 \%$ within 1 hour to $85 \% \pm 1.6 \%$ at 6 hours. In the case of ACSC-Fe-bLf NCs, the percentage of endocytosis was reduced from 1 hour to -6 hours; however, a slight increase by the end of 12 hours (23\%) was observed (Figure 2E). The lower in vitro uptake of alginate could mainly correspond to the surface charge (zeta potential), which was found to be -1.29 due to the outer coating of alginate. Cells are also negatively charged, and this may be the reason as to why the ACSC NCs showed lower cellular uptake when compared to CSC NCs (where chitosan is present in the outer layer). Among all these inhibitors, chlorpromazine-blocked (2.4-fold) and sodium azide-blocked (2.4-fold) pathways led to a significant 
A

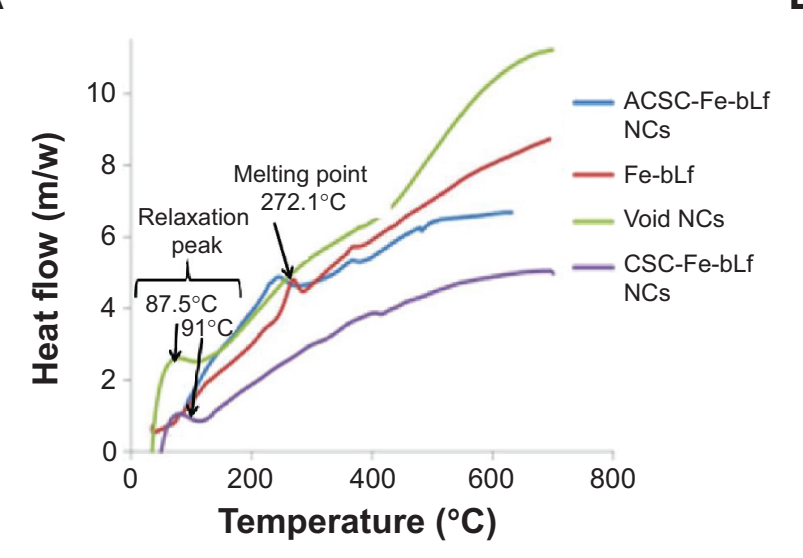

B

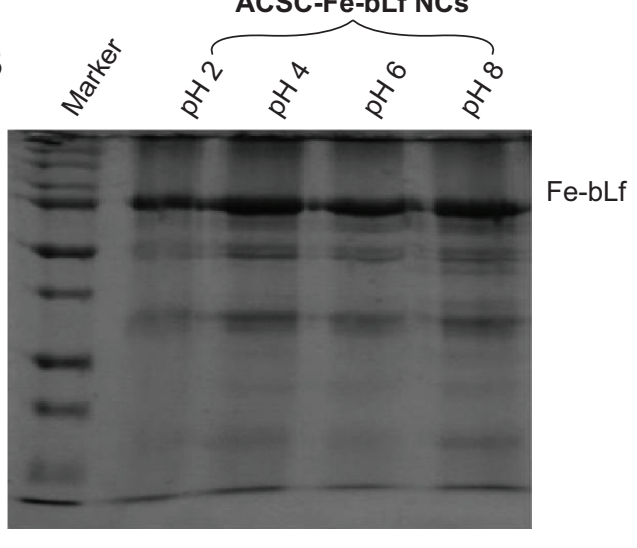

C

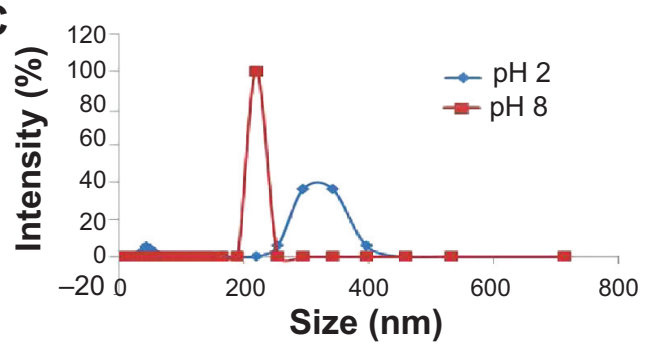

D
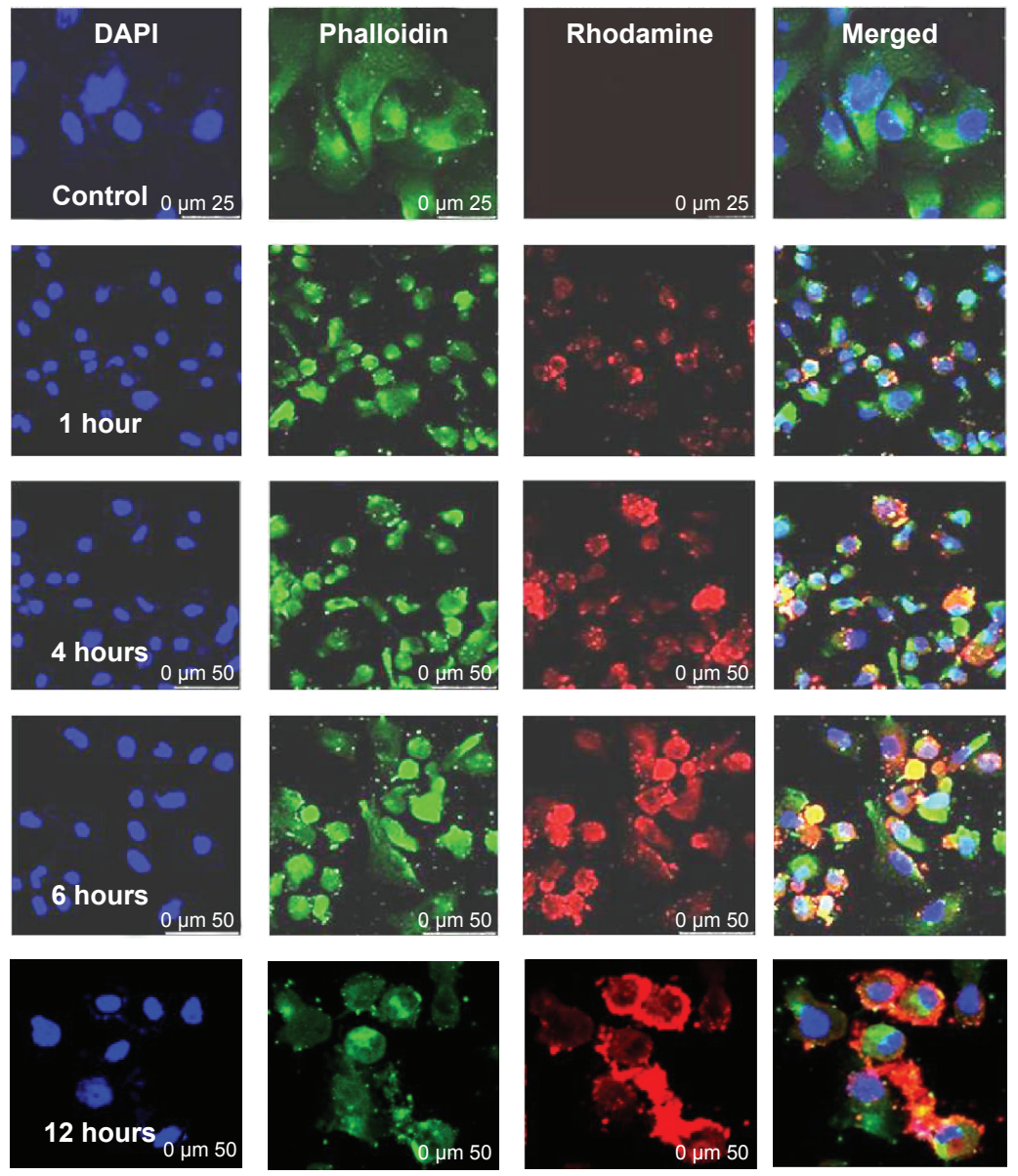

Figure 2 (Continued) 

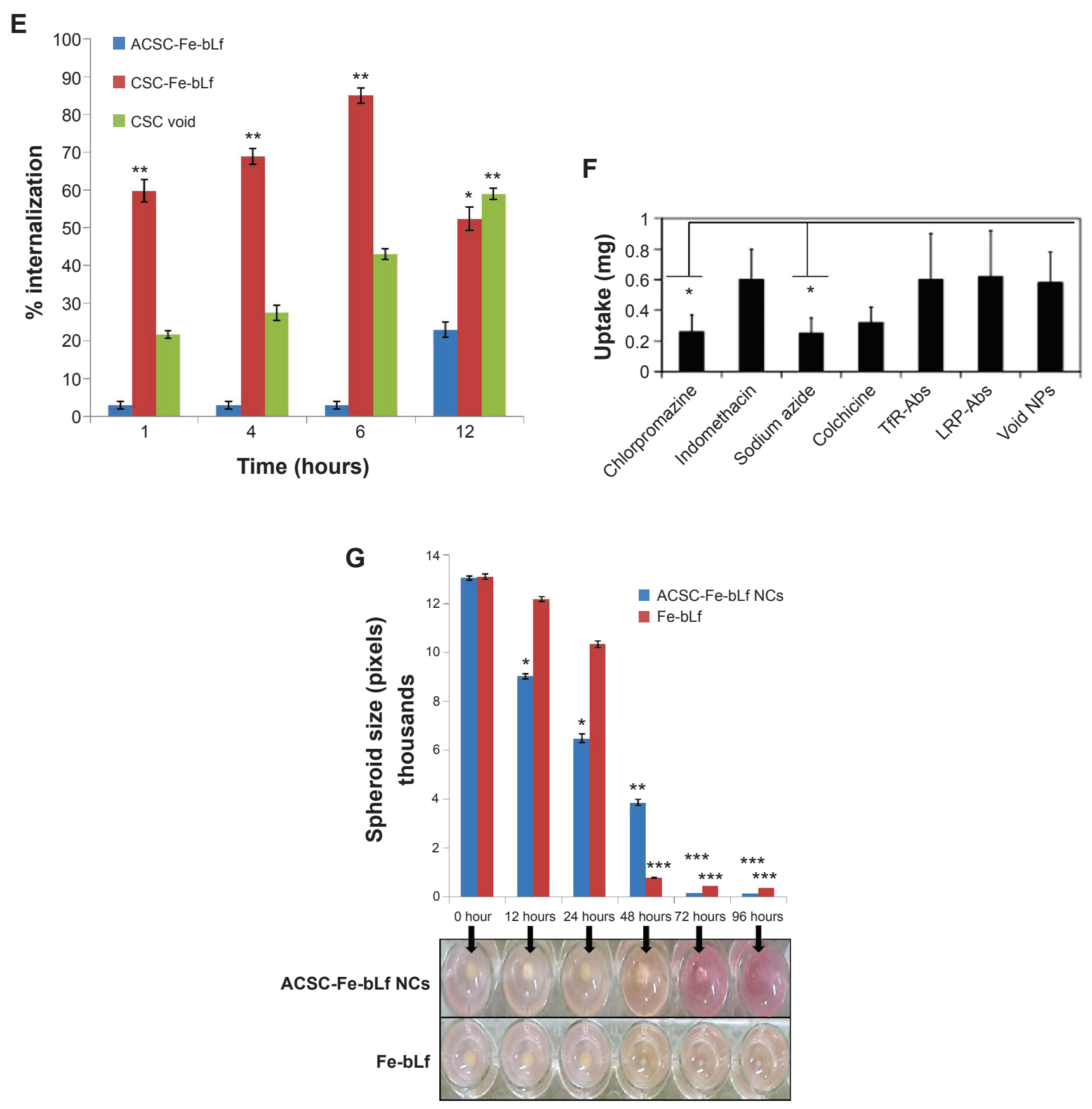

Figure 2 Stability and in vitro internalization efficacy of ceramic NCs.

Notes: (A)The differential scanning calorimetry curve showed modification in the melting point and the enthalpy of melting of NCs. (B) Sodium dodecyl sulfate-polyacrylamide gel electrophoresis showed the stability of $\mathrm{NC}$-encapsulated Fe-bLf at varying $\mathrm{pH}(2-8)$. (C) It was observed using dynamic light scattering that alginate layer was shed off from ACSC-Fe-bLf NCs at alkaline $\mathrm{pH}$ to expose the CSC-Fe-bLf NCs. (D) Confocal microscopy confirmed successful internalization of rhodamine-labeled NCs in I hour, which was found to increase with time. (E) Flow cytometric analysis shows an increase in the internalization of rhodamine-loaded CSC-Fe-bLf NCs compared to void CSC NCs. (F) NCs enter the cells mainly via clathrin-mediated endocytosis and energy-mediated pathways. (G) $3.3 \mathrm{mg} / \mathrm{mL}$ of Fe-bLf loaded in NCs induced a I 30 -fold reduction in the size of multicellular tumor spheroids at 72 hours and 96 hours. Data represent mean \pm standard error of the mean. Experiments were repeated three times independently with similar results. $* P<0.05 ; * * P<0.005 ; * * * P \leq 0.0005$.

Abbreviations: ACSC, alginate-enclosed chitosan-coated calcium phosphate; CSC, chitosan-coated calcium phosphate; DAPI, 4',6-diamidino-2-phenylindole; Fe-bLf, ironsaturated bovine lactoferrin; LRP, low-density lipoprotein receptor; m/w, molecular weight; NCs, nanocapsules/nanocarriers; TfR, transferrin receptor.

$(P \leq 0.05)$ reduction in the uptake of NCs (Figure 2F). Multicellular tumor spheroids are known to mimic the in vivo tumor growth. ${ }^{27}$ The results from 3D tumor spheroid assay as observed from the graph (Figure $2 \mathrm{G}$ ) revealed that
MDA-MB-231 multicellular tumor spheroids treated with $3.3 \mathrm{mg} / \mathrm{mL}$ of ACSC-Fe-bLf NCs for 96 hours showed complete dissociation of the spheroids at 72 hours and 96 hours (represented in the wells). The tumor spheroids treated with 
non-nano-Fe-bLf on the other hand, showed comparatively slower reduction rates and the tumor spheroid did not completely dissociate at 72 hours or 96 hours.

\section{Anticancer efficacy of ACSC-Fe-bLf NCs in vitro}

The results of MTT after 10 hours of incubation with the highest concentration $(3.57 \mathrm{mg} / \mathrm{mL})$ of NCs showed that the cell viability of cells treated with CSC-Fe-bLf (17.6\%) was significantly low $(P \leq 0.005)$ when compared to the cell viability of cells treated with ACSC-Fe-bLf (32\%) and void (63.3\%). The $\mathrm{IC}_{50}$ values as determined for void NCs was $3.83 \mathrm{mg} / \mathrm{mL}$, for ACSC-Fe-bLf it was $1.69 \mathrm{mg} / \mathrm{mL}$, and for CSC-Fe-bLf it was $1.20 \mathrm{mg} / \mathrm{mL}$ (Figure 3A). The results from CyQUANT after $10 \mathrm{~h}$ showed that CSC-Fe-bLf(42.8\%) significantly lowered $(P \leq 0.005)$ the cell proliferation when compared to void NCs $(92.2 \%)$ and ACSC-Fe-bLf (93\%) (Figure 3B).

The results were reanalyzed after 20 hours of incubation, and the MTT results confirmed that cell viability was significantly $(P \leq 0.005)$ lowered in CSC-Fe-bLf NCs (11.4\%) when compared to ACSC-Fe-bLf NCs (32\%) and void NCs $(63 \%)$. The $\mathrm{IC}_{50}$ values for void NCs were found to be $4.8 \mathrm{mg} / \mathrm{mL}$, for ACSC-Fe-bLf NCs it was $1.62 \mathrm{mg} / \mathrm{mL}$, and for CSC-Fe-bLf NCs it was $1.19 \mathrm{mg} / \mathrm{mL}$ (Figure 3C). The cell proliferation results from CyQUANT after 20 hours showed that CSC-Fe-bLf (15.3\%) significantly ( $P \leq 0.005)$ lowered the cell proliferation when compared to ACSCFe-bLf NCs (63\%) and void NCs (72.6\%) (Figure 3D). The clonogenic assay results also revealed that CSC-Fe-bLf showed a substantial reduction in the clonogenic potential of MDA-MB-231 cells (Figure S4).
A
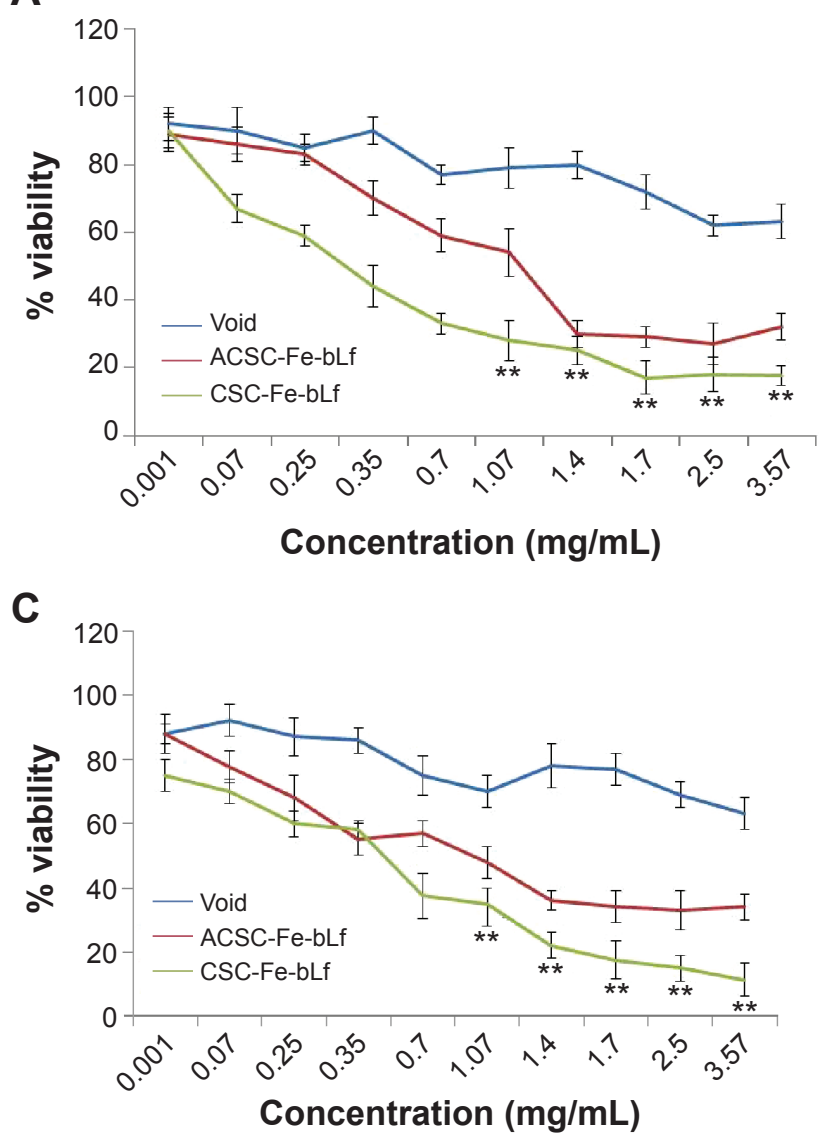

B
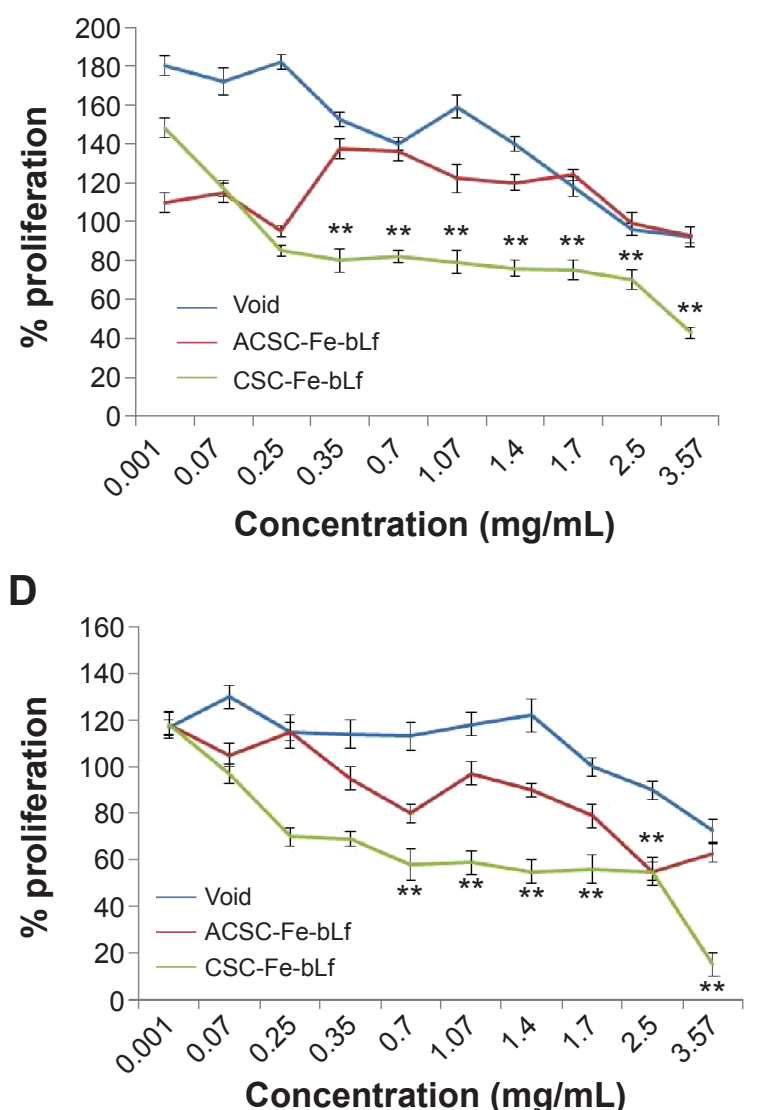

Figure 3 In vitro anticancer efficacy of Fe-bLf-encapsulating ceramic NCs.

Notes: (A) The IC $\mathrm{IC}_{50}$ values as determined using MTT at 10 hours for void NCs was $3.83 \mathrm{mg} / \mathrm{mL}$, for ACSC-Fe-bLf it was $1.69 \mathrm{mg} / \mathrm{mL}$, and for CSC-Fe-bLf it was I.20 mg/mL. (B) The results from CyQUANT after 10 hours showed that CSC-Fe-bLf (42.8\%) significantly lowered $(P \leq 0.005)$ the cell proliferation when compared to void NCs $(92.2 \%)$ and ACSC-Fe-bLf NCs (93\%). (C) The IC ${ }_{50}$ values determined using MTT at 20 hours for void NCs was found to be $4.8 \mathrm{mg} / \mathrm{mL}$, for ACSC-Fe-bLf NCs it was I.62 mg/mL, and

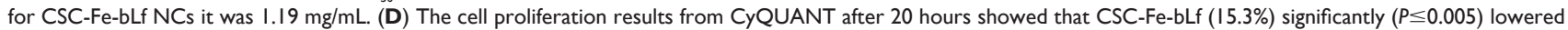
the cell proliferation when compared to ACSC-Fe-bLf NCs (63\%) and void NCs (72.6\%). Data represent mean \pm standard error of the mean. Experiments were repeated three times independently with similar results $* * P \leq 0.005$.

Abbreviations: ACSC, alginate-enclosed chitosan-coated calcium phosphate; CSC, chitosan-coated calcium phosphate; Fe-bLf, iron-saturated bovine lactoferrin; NCs, nanocapsules/nanocarriers. 


\section{Determining the in vivo anticancer efficacy of Fe-bLf-loaded ACSC NCs}

In the preventive study, mice were fed on three diet groups. Control or no Fe-bLf NCs diet, Fe-bLf NCs diet for 65 days (group 1), and Fe-bLf NCs diet only till the 45th day (group 2). Approximately $3.38 \times 10^{9} \mathrm{NCs}$ containing $12 \mathrm{~g}$ Fe-bLf $/ \mathrm{kg}$ diet were administered orally in the mice. The tumor appeared in mice after 10 days of injection, and once the tumor reached a diameter of $\sim 45.6 \mathrm{~mm}^{3}$, it was regressed by injecting Taxol in control mice group. Reinjection of $1 \times 10^{6}$ MDA-MB-231 cancer cells on the 45th day was performed to mimic the situation of tumor recurrence. The control group (previously injected with Taxol) showed development of tumor. This clearly showed that Taxol did not have continuous protective effects on the mice. On the other hand, mice fed with Fe-bLf NCs (both diet 1 and 2) did not show any sign of tumor growth in either the first challenge or the second challenge.

In our previously published studies, ${ }^{9}$ we have reported that during the preventive studies mice fed with Fe-bLf NCs did not develop tumor at all. A similar observation was made in the present study, where the mice fed with Fe-bLf NCs when injected with breast cancer cells did not develop tumor. Previously, we have shown that Fe-bLf NCs inhibited the cellular expression of survivin and its splice variants; downregulated key cancer stem cell markers such as CD133, CD44, CD166, and EpCAM; and also prevented angiogenesis and neo-angiogenesis. These reasons may account for the absence of tumor development in the preventive study.

As shown in Figure 4B, there was no effect on the body weight in controls group that had developed tumors and so is the case with the treatment groups. In fact, the average body weight of the treatment groups was more in comparison to controls and the mice remained healthy because Fe-bLf is a natural defense protein with anticancer properties. ${ }^{19,28}$ body conditional score of $0-4$ have indicated that the animals were healthy without any of the side effects posed by nanocarrier-based therapy.

In the treatment studies, it was observed that the tumor size increased irreversibly in mice fed on control diet ( 2.25 -fold) and on void NCs diet (2.05-fold). The mice fed on ACSC-Fe-bLf NCs diet showed a radical decrease (3-fold) in the tumor size on the 65th day, which kept on decreasing until the 80th day (10-fold) and finally there was no tumor in the mice on 85th day. On the other hand, mice injected with the combination of Taxol and Doxorubicin, although did show an initial decrease from 55th to 65 th day (3-fold), the tumor size was found to increase again on the 65th day until the 85th day (3.4-fold) (Figure 4C). These results clearly showed that Taxol did not have a continuous protective effect on the mice. Since the increase in tumor size was only found after 15 days of injection, it is possible that both the drugs would have been removed from the mice body. ${ }^{29,30}$ Both Taxol and Doxorubicin are also commonly known to induce drug resistance in breast cancer. ${ }^{31,32}$

\section{Assessment of in vivo biodistribution and internalization mechanism}

Organs involved in NCs internalization including intestine (Figure 5A-a,b), brain (Figure 5A-c,d), and key components in reticulo-endothelial system; kidneys (Figure 5A-e,f) showed no abnormality. The anatomy of controlled versus treated sections retained their integrity and tissue pathology, showing a minimal damage to these organs with the treatment (Figure 5A). In addition to tissue pathology, biodistribution of ACSC NCs was done based on the Fe-bLf functionalized on the NCs. In the case of treatment groups (Figure 5B), a characteristic immunoreactivity (brown color due to immunoreactivity) of Fe-bLf was seen. As represented, in the case of brain tissues, a mild immunoreactivity of Fe-bLf was observed (Figure 5B-b). Liver showed mild immunoreactivity (Figure 5B-c) as a function of biodegradability of the NCs. Furthermore, ileum (Figure 5B-f) showed intense Fe-bLf immunoreactivity corresponding to the proposed transcytosis of the NCs.

A significant increase in iron levels $(P \leq 0.05)$ in the case of the reticulo-endothelial organs, liver $(1.3 \pm 0.1 \mathrm{mg} / \mathrm{ml})$ and spleen $(1.7 \pm 0.1 \mathrm{mg} / \mathrm{ml})$, was observed. Similarly, increased intestinal (1.5 \pm 0.03 -fold) iron concentration was noticed that corresponds to the transcytosis. In case of brain tissues the iron concentration was found to be (1.4 \pm 0.1 -fold) compared to control. Most importantly, there was a 5.33 -fold increase in iron levels in tumor, which was highly significant $(P \leq 0.005)$ when compared to the untreated control (Figure 6A). Furthermore, based on the fact that anticancer Fe-bLf was positive for Prussian blue staining, co-localization of NCs along with blood vessels was further investigated. A substantial amount of FebLf-loaded NCs was still clearly observed around the vascular region of the brain tissue slices (Figure 6B and C) using Prussian blue and CD31 double staining. At high magnification (100×), NCs were observed to be located in intracellular regions.

\section{Gene and miRNA analysis for the expression of various receptors and miRNA responsible for nanocapsule uptake} The results showed that in the intestine, miR196 (1.175fold), miR200b (1.175-fold), and miR485 (1.3-fold) showed effective upregulation, whereas all others were downregulated. In the liver, only miR210 (1.35-fold) and miR584 (1.175-fold) were found to be upregulated, whereas miR485 did not show any change in expression and all others were 
A

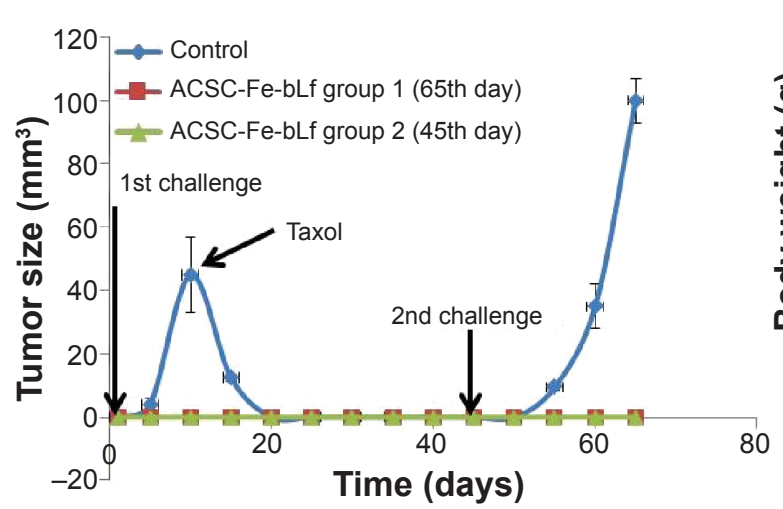

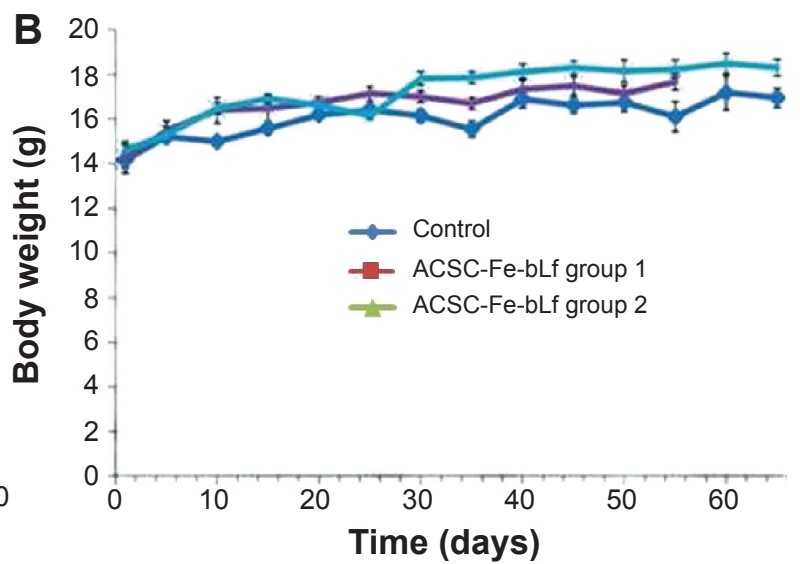

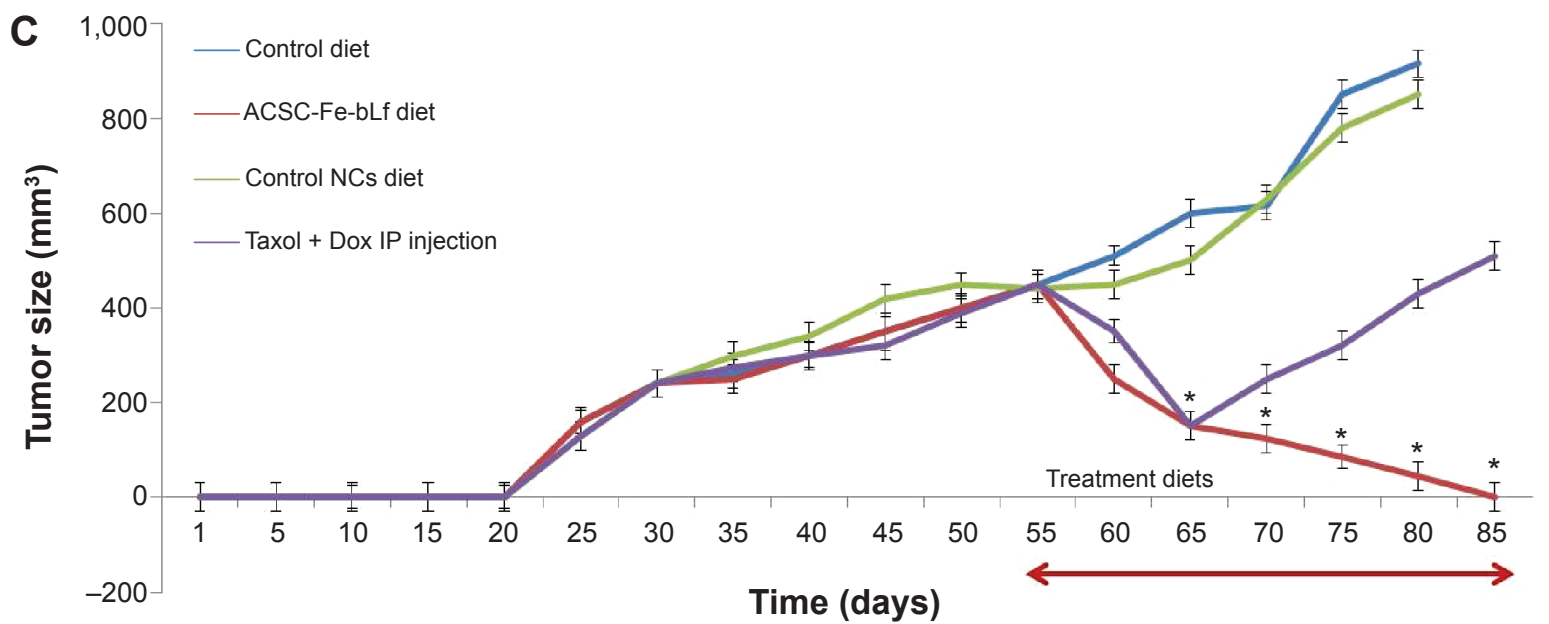

Figure 4 In vivo antitumor efficacy of ceramic NCs.

Notes: (A) Within I week after the injection of $10^{7}$ cancer cells, tumors $\left(\sim 45.6 \mathrm{~mm}^{3}\right)$ were developed in control diet-fed mice and were terminated by injecting Taxol (IP) when challenged for the second time, $\sim 100.3 \mathrm{~mm}^{3}$ tumors were observed in 4 weeks. In neither of the cases (first challenge or the second challenge), significant tumors were developed in the treatment groups of mice. (B) Average body weight of the control group remained at I4.4I g, whereas treatment groups showed an increase in body weight up to $17.32 \mathrm{~g}$. (C) ASCS-Fe-bLf NC diet showed I0-fold reduction in tumor volume from 55 th day to 80 th day, and on 85 th day, the tumor was completely absent. Data represent mean \pm standard error of the mean $(n=5)$. $* P<0.05$.

Abbreviations: ACSC, alginate-enclosed chitosan-coated calcium phosphate; Dox, doxorubicin; Fe-bLf, iron-saturated bovine lactoferrin; IP, intraperitoneal; NCs, nanocapsules/nanocarriers.

downregulated. In the spleen, miR122 (1.1-fold) was slightly upregulated, miR196 (1.43-fold) and miR485 (1.375-fold) were highly upregulated, and miR200b and miR320 did not show any change, whereas others were downregulated. In the brain, miR122 (1.18-fold), miR214 (1.23-fold), and miR485 (1.25-fold) were found to be upregulated, whereas all others were found to be downregulated (Figure 6D). Lactoferrin was shown to be an LRP as well as a TfR ligand. ${ }^{33,34}$ Taking into consideration the fact that lactoferrin and transferrin share 60\%-80\% sequence homology, gene expression levels of TfRs were analyzed along with LRPs. An increased expression of Lf receptors in the tissues from the NC-fed animals compared to control tissues gives a clue for possible internalization using these receptors. More importantly, higher LRP (Figures 6E and S5) and TfR (Figures 6F and S6) levels were detected in the intestine compared to control tissue or untreated cells, which suggest that when taken orally, intestinal uptake of these NCs occurs for further targeting the tumor site via the systemic circulation. The gene expressions of LRP and TfR isoforms MDA-MB-231 cells were also studied in order to compare the receptor-mediated internalization in vitro and in vivo.

Thus, based on the surface receptor-ligand chemistry, it could be possible that bLf could guide the NCs for enhanced internalization.

\section{Analysis of blood and serum profile of mice}

In a previously published study, ${ }^{7}$ we reported that $1.2 \%$ $(\mathrm{w} / \mathrm{w})$ diet of Fe-bLf raised the iron levels in serum from $0.0053 \%$ to just $0.0069 \%$, which was statistically insignificant $(P \geq 0.05) .{ }^{8}$ The pharmacokinetic studies conducted in the same study ${ }^{8}$ showed that oral delivery of Fe-bLf ensured presence of Fe-bLf for 3 hours in serum postfeeding, and 
A
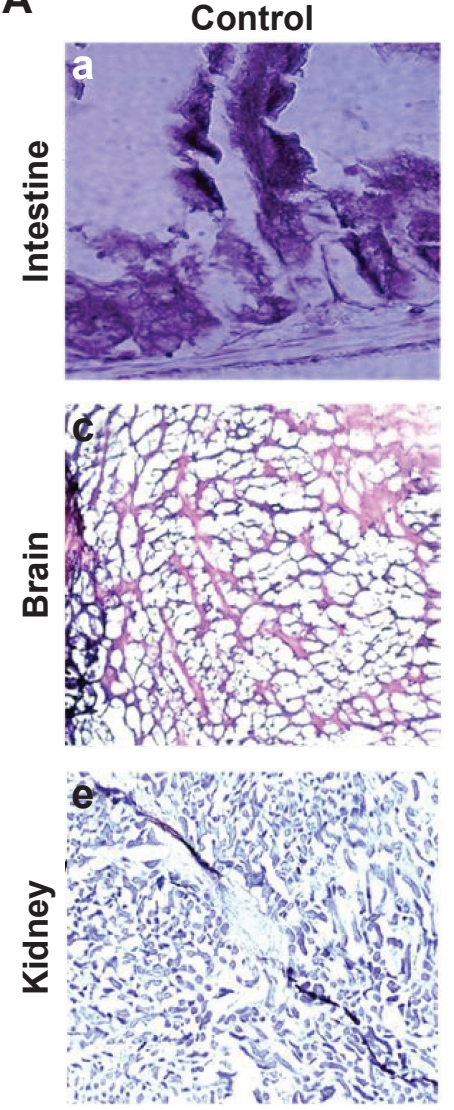

Treated
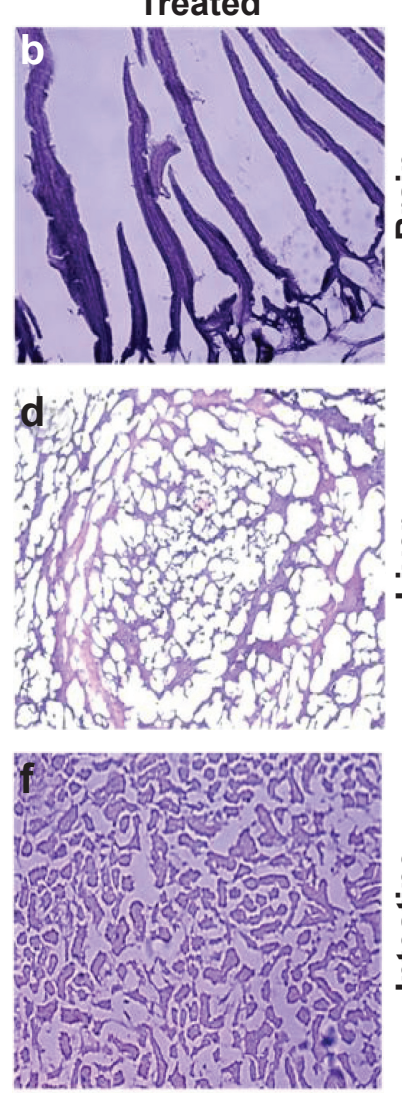

B
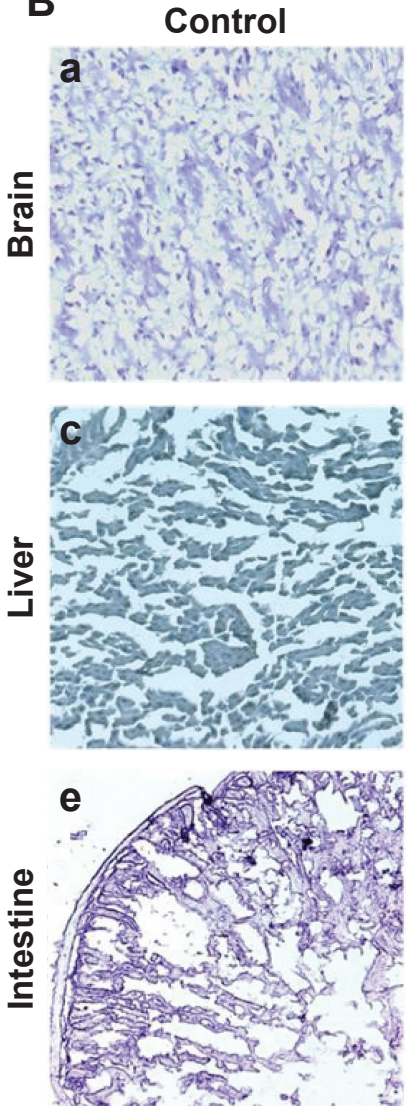

Treated
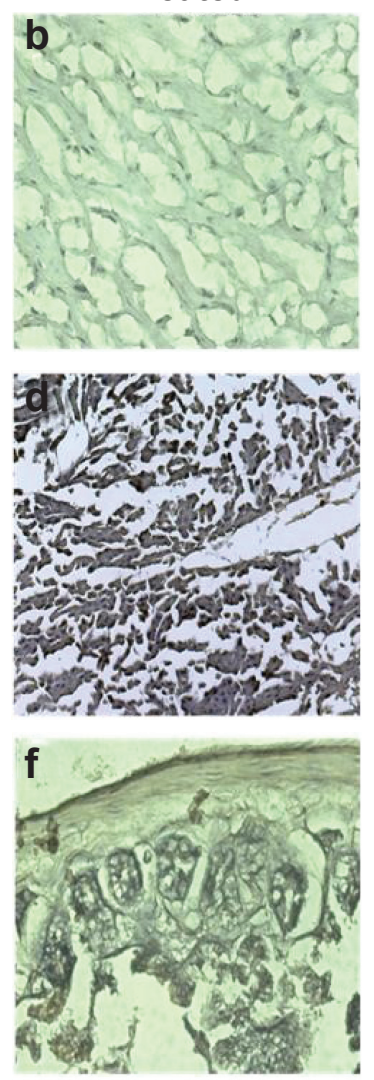

Figure 5 Histological analysis for cytotoxicity studies.

Notes: (A) Tissue pathology observation after the treatment is represented in the figure. Hematoxylin and eosin staining was carried out in order to observe the tissue integrity in the control and treatment groups. Five-micrometer-thin slices of intestine (TS), kidney (LS), and brain (LS) from control (a, c, and e) and treated (b, d, f) mice were stained with hematoxylin and eosin was used as a counterstain. Observations were made under I00X oil immersion objective. (B) Immunohistochemical localization of ACSC-Fe-bLf NCs using anti-lactoferrin antibody. Brain (LS), liver (LS), and intestine (TS) sections from control (a, c, e) and treated (b, d, f) groups are shown.

Abbreviations: ACSC, alginate-enclosed chitosan-coated calcium phosphate; Fe-bLf, iron-saturated bovine lactoferrin; LS, longitudinal section; NCs, nanocapsules/ nanocarriers; TS, transverse section.

the levels of Fe-bLf were not detectable beyond 72 hours, thus ensuring clearance of protein from the body.

Our findings, shown in Table 2, are as follows. The hemoglobin level showed a 1.18 -fold upsurge in mice treated with Fe-bLf and 1.26-fold increase in ACSC-Fe-bLf NC-treated mice when compared to untreated mice. The hematocrit levels were found to increase by 1.29-fold and 1.49-fold in Fe-bLf and ACSC-Fe-bLf NCs, respectively. The iron concentration in both liver and spleen was increased in the treatment groups (1.11-, 1.18-fold and 1.06-, 1.090fold, respectively). The serum iron concentration was found to increase by 1.137 -fold and 1.32 -fold in both liver and spleen, respectively, and the serum calcium concentration was also found to be upregulated by 1.16- and 1.235-fold, respectively. Anemia, a common phenomenon as result of cancer treatment, is caused by bleeding, hemolysis, deficiency of erythropoietic factors, gut infections, diarrhea, and other nutritional deficiencies. ${ }^{35,36}$ Long-term chemotherapy causes damage to the blood cells, in turn impairing erythropoiesis. In this paper we have shown clearly that Fe-bLf and Fe-bLf NCs significantly increase the serum iron levels, RBC count, hemoglobin count, etc. We have already shown that bLf and its iron-saturated forms have immunomodulatory properties and it leads to increase in iron, hemoglobin, and RBC count. ${ }^{8,37}$ Therefore, Fe-bLf can act as an alternative therapy for the patients undergoing chemotherapy as these patients are generally anemic. ${ }^{38}$

\section{Conclusion}

With current and predicted increase in breast cancer cases worldwide including Australia and side effects of the cytotoxic chemotherapy, it is becoming increasingly important for medical scientists to find safe, less toxic, and effective alternative therapies. In our previous publications, we reported that Fe-bLf in combination with lower doses of toxic anticancer chemotherapy was found to be more effective in various 
A

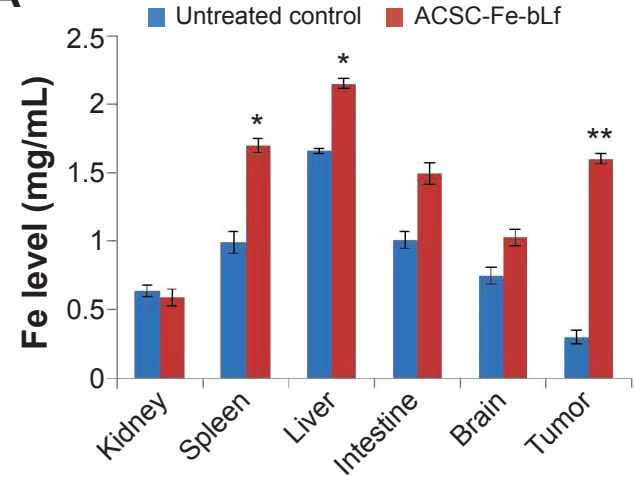

B

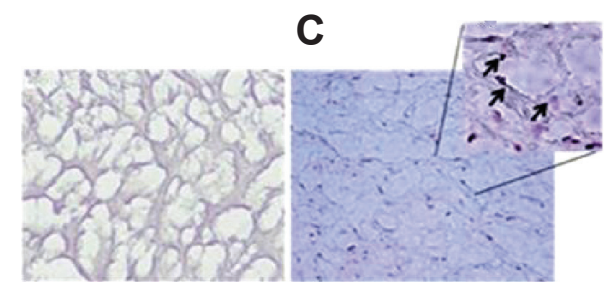

E

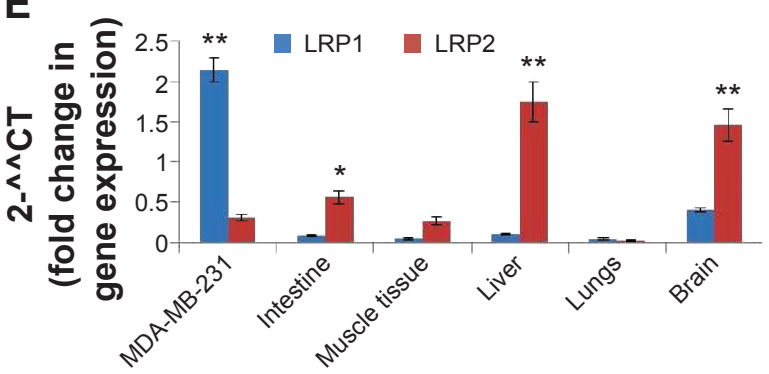

D

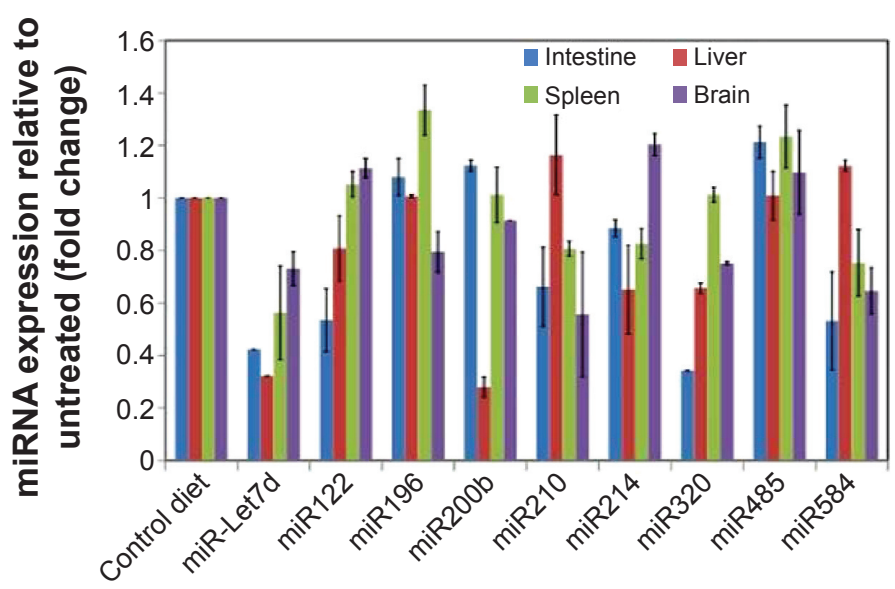

$\mathbf{F}$

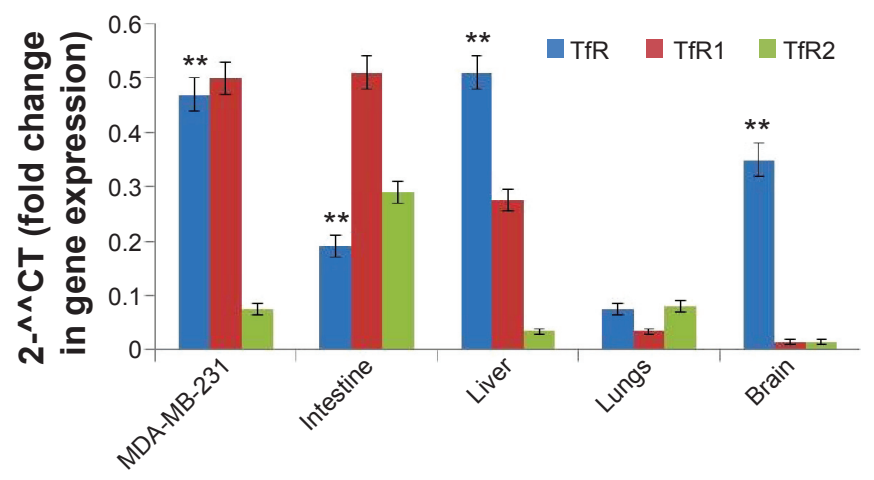

Figure 6 Expression of key receptors involved in the uptake of ceramic NCs.

Notes: (A) Significant levels of increased iron in treatment groups (red bars) compared to control (blue) in case of spleen, liver, intestine, brain and tumor were observed. (B) Lower left panel shows control group negative for Prussian blue staining. (C) Inset shows internalization of Fe-bLf-loaded ACSC NCs near the CD3I-stained area. (D) miRNA expression analysis from intestine, liver, spleen, and brain was carried out in Fe-bLF-NC-treated mice. (E) LRPI expression was comparatively higher in vitro when compared to in vivo. LRP2 mRNA levels were elevated in mice liver, brain, and intestine tissues. (F) Expression of TfR and its isoforms was high in MDA cells, liver, brain, and intestinal tissues. Data represent mean \pm standard error of the mean. Experiments were repeated three times independently with similar results. $* * P<0.005 ; * P<0.05$. Abbreviations: ACSC, alginate-enclosed chitosan-coated calcium phosphate; Fe-bLf, iron-saturated bovine lactoferrin; LRP, low-density lipoprotein receptor; miRNA, micro-RNA; NCs, nanocapsules/nanocarriers; TfR, transferrin receptor.

Table 2 Serum iron, serum calcium, and blood hematological profile of control and experimental mice with bovine lactoferrin-fed groups and mice fed on control diet

\begin{tabular}{llll}
\hline Organ/cells & Fe-bLf & ACSC-Fe-bLf NCs & Control diet \\
\hline Hemoglobin level $(\mathrm{g} / \mathrm{dL})$ & $18.0 \pm 0.5^{*}$ & $19.2 \pm 2.5$ & $15.2 \pm 1.5$ \\
Hematocrit level $(\%)$ & $65.5 \pm 5.5^{*}$ & $75.5 \pm 5.0$ & $50.5 \pm 2.0$ \\
Liver Fe $(\mu \mathrm{g} / \mathrm{g})$ & $80 \pm 10^{*}$ & $85.6 \pm 10$ & $72 \pm 15$ \\
Spleen Fe $(\mu \mathrm{g} / \mathrm{g})$ & $175 \pm 21^{*}$ & $180 \pm 14$ & $165 \pm 10$ \\
RBCs $\left(\times 10^{6} / \mathrm{mm}^{3}\right)^{\mathrm{a}}$ & $8.5 \pm 2.5^{* *}$ & $9.5 \pm 1.0$ & $5.5 \pm 1.0$ \\
Reticulocytes, $\times 10^{9}$ cells/L & $405 \pm 25^{*}$ & $450 \pm 20$ & $349 \pm 15$ \\
Reticulocyte hemoglobin content, $\mathrm{Pg}$ & $20 \pm 6^{* *}$ & $24 \pm 5$ & $12 \pm 4$ \\
Serum iron $(\mu \mathrm{g} / \mathrm{g})$ & $165 \pm 25^{* *}$ & $192 \pm 12$ & $145 \pm 20$ \\
Serum calcium $(\mathrm{mg} / \mathrm{dL})$ & $9.9 \pm 0.8^{*}$ & $10.5 \pm 2.0$ & $8.5 \pm 1.8$ \\
\hline
\end{tabular}

Notes: a Mean values of RBC counts were recorded in blood samples collected directly from the heart at the time of autopsy. Data are expressed as mean \pm SD. $* * P<0.00$ I is the highly significant value from the control. $* P<0.05$ is the significance value from the control.

Abbreviations: ACSC, alginate-enclosed chitosan-coated calcium phosphate; Fe-bLf, iron-saturated bovine lactoferrin; NCs, nanocapsules/nanocarriers; RBC, red blood cell. 


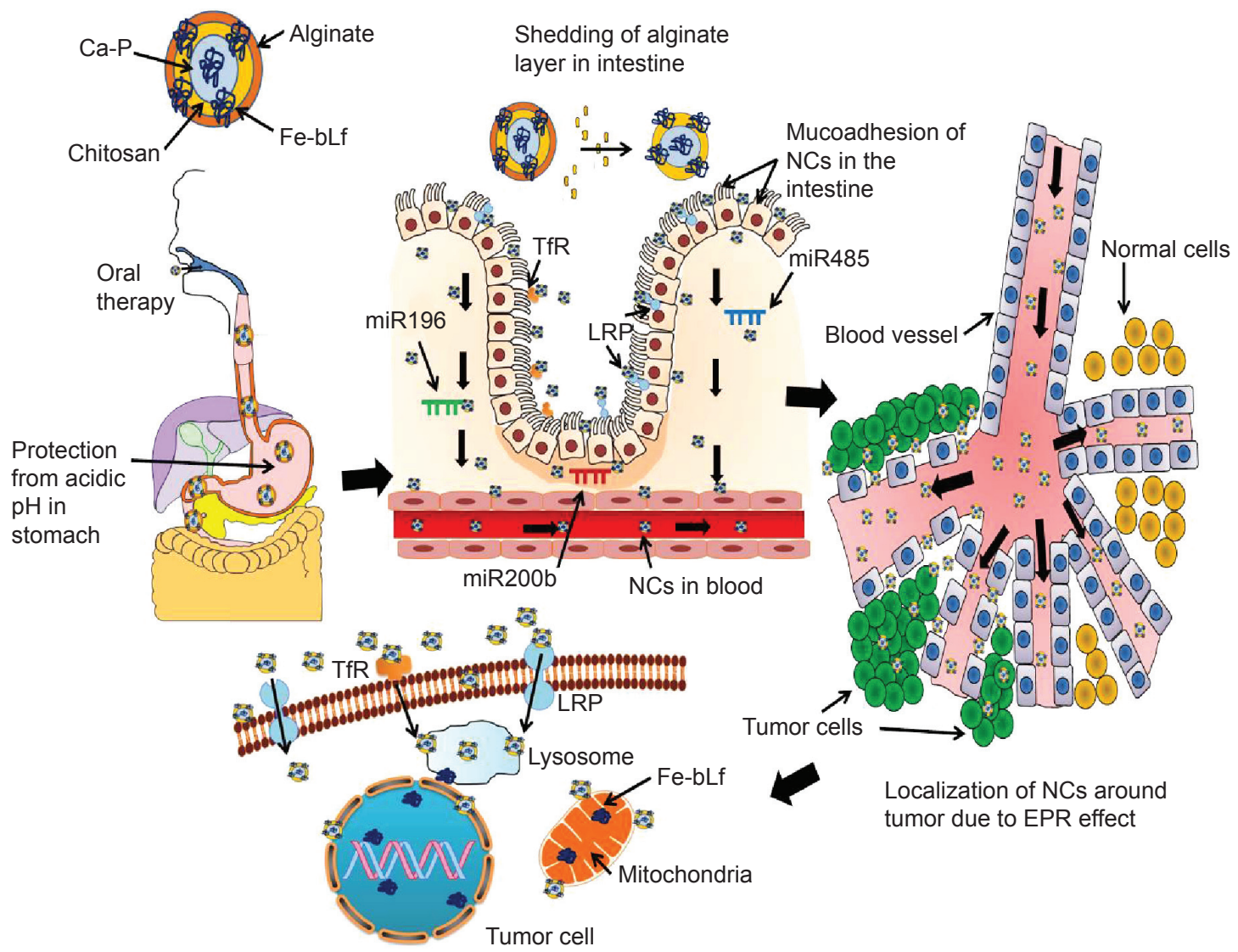

Figure 7 Mechanism of uptake of ACSC-Fe-bLf.

Notes: The double coating of alginate and chitosan protects (ACSC-Fe-bLf) Fe-bLF from acidic degradation in the stomach. The CSC-Fe-bLf NCs also lead to an upregulation of miRNAs responsible for iron metabolism mainly miRI96, miR200b, and miR485 in the intestine. This enhances their uptake by the intestinal cells. Because Fe-bLf is a ligand for TfR and low-density lipoprotein receptor, the CSC-Fe-bLf NCs are endocytosed in the cancer cells, using these receptors. Control release of Fe-bLf from the NCs executes the antitumor efficacy by interfering with molecular mechanisms involved in the cellular apoptosis.

Abbreviations: ACSC, alginate-enclosed chitosan-coated calcium phosphate; Ca-P, calcium phosphate; EPR, enhanced permeability and retention; Fe-bLf, iron-saturated bovine lactoferrin; LRP, low-density lipoprotein receptor; miRNA, micro-RNA; NCs, nanocapsules/nanocarriers; TfR, transferrin receptor.

cancer types; however, recently, we found that Fe-bLf-loaded ACSC NCs alone showed more promising anticancer efficacy in both in vitro and in vivo studies (Figure 7). The NCs proved to be incredibly antitumorigenic based on the fact that none of the mice injected with breast cancer cells developed tumors in the xenograft models. Body condition scoring and tissue pathology designated safe and biocompatible nature of these NCs. Finally, novel new-generation-targeted natural and safe molecule-based nanomedicine and nanonutraceutical approaches could enhance further the antitumor efficacy to kill tumor cells sparing the normal body cells along with the lower doses of toxic chemotherapies.

\section{Acknowledgments}

The authors thank the Australia-India Strategic Research Fund and National Health and Medical Research Council for financial support. The authors thank Dr Nick Branson for his assistance with animal work and for his technical support and guidance with the animal experimental procedures. The authors also thank the upper animal house staff, in particular $\mathrm{T}$ Thorpe, A Cooper, and B Newell for providing help in handling the animals.

\section{Disclosure}

The authors have no other relevant affiliations or financial involvement with any organization or entity with a financial interest in or financial conflict with the subject matter or materials discussed in the manuscript apart from those disclosed. No writing assistance was utilized in the production of the manuscript. The authors report no other conflicts of interest in this work.

\section{References}

1. Evangelista AL, Santos EM. Cluster of symptoms in women with breast cancer treated with curative intent. Support Care Cancer. 2012;20(7): 1499-1506.

2. Cuzick J, DeCensi A, Arun B, et al. Preventive therapy for breast cancer: a consensus statement. Lancet Oncol. 2011;12(5):496-503. 
3. Partridge AH, Burstein HJ, Winer EP. Side effects of chemotherapy and combined chemohormonal therapy in women with early-stage breast cancer. J Natl Cancer Inst Monogr. 2001;30:135-142.

4. Shapiro CL, Recht A. Side effects of adjuvant treatment of breast cancer. N Engl J Med. 2001;344(26):1997-2008.

5. Broeyer FJ, Osanto S, Ritsema van Eck HJ, et al. Evaluation of biomarkers for cardiotoxicity of anthracyclin-based chemotherapy. J Cancer Res Clin Oncol. 2008;134(9):961-968.

6. Rogan MP, Geraghty P, Greene CM, O’Neill SJ, Taggart CC, McElvaney NG. Antimicrobial proteins and polypeptides in pulmonary innate defence. Respir Res. 2006;7(29):1-11.

7. Kanwar JR, Palmano KP, Sun X, et al. 'Iron-saturated' lactoferrin is a potent natural adjuvant for augmenting cancer chemotherapy. Immunol Cell Biol. 2008;86(3):277-288.

8. Kanwar JR, Mahidhara G, Kanwar RK. Novel alginate-enclosed chitosan-calcium phosphate-loaded iron-saturated bovine lactoferrin nanocarriers for oral delivery in colon cancer therapy. Nanomedicine. 2012;7(10):1521-1550.

9. Kanwar JR, Mahidhara G, Roy K, et al. Fe-bLf nanoformulation targets survivin to kill colon cancer stem cells and maintains absorption of iron, calcium and zinc. Nanomedicine (Lond). Epub 2014 July 14.

10. Gan Q, Wang T. Chitosan nanoparticle as protein delivery carrier systematic examination of fabrication conditions for efficient loading and release. Colloids Surf B Biointerfaces. 2007;59(1):24-34.

11. Dustgani A, Farahani VE, Imani M. Preparation of chitosan nanoparticles loaded by dexamethasone sodium phosphate. Iran J Pharm Sci. 2008;4(2):111-114.

12. Suzuki YA, Lonnerdal B. Characterization of mammalian receptors for lactoferrin. Biochem Cell Biol. 2002;80(1):75-80.

13. Jiang R, Lopez V, Kelleher SL, Lonnerdal B. Apo- and holo-lactoferrin are both internalized by lactoferrin receptor via clathrin-mediated endocytosis but differentially affect ERK-signaling and cell proliferation in Caco-2 cells. J Cell Physiol. 2011;226(11):3022-3031.

14. Vinci M, Gowan S, Boxall F, et al. Advances in establishment and analysis of three-dimensional tumor spheroid-based functional assays for target validation and drug evaluation. BMC Biol. 2012;10(1):29.

15. Kanwar JR, Berg RW, Yang Y, et al. Requirements for ICAM-1 immunogene therapy of lymphoma. Cancer Gene Ther. 2003;10(6):468-476.

16. Kanwar JR, Shen WP, Kanwar RK, Berg RW, Krissansen GW. Effects of survivin antagonists on growth of established tumors and B7-1 immunogene therapy. J Natl Cancer Inst. 2001;93(20):1541-1552.

17. Liao Y, Lönnerdal B. miR-584 mediates post-transcriptional expression of lactoferrin receptor in Caco-2 cells and in mouse small intestine during the perinatal period. Int J Biochem Cell Biol. 2010;42(8):1363-1369.

18. Epple M, Ganesan K, Heumann R, et al. Application of calcium phosphate nanoparticles in biomedicine. J Mater Chem. 2010;20(1):18-23.

19. Gades MD, Stern JS. Chitosan supplementation and fat absorption in men and women. J Am Diet Assoc. 2005;105(1):72-77.

20. Tugcu-Demiroz F, Acarturk F, Takka S, Konus-Boyunaga O. Evaluation of alginate based mesalazine tablets for intestinal drug delivery. Eur J Pharm Biopharm. 2007;67(2):491-497.

21. Zhang L, Gu FX, Chan JM, Wang AZ, Langer RS, Farokhzad OC. Nanoparticles in medicine: therapeutic applications and developments. Clin Pharmacol Ther. 2008;83(5):761-769.
22. Lu X, Wen Z, Li J. Hydroxyl-containing antimony oxide bromide nanorods combined with chitosan for biosensors. Biomaterials. 2006;27(33): 5740-5747.

23. Moroni A, Drefko W, Thone G. Formulations of zero-order, pHdependent, sustained release matrix systems by ionotropic gelation of alginate-containing mixtures. Drug Dev Ind Pharm. 2011;37(2): 216-224.

24. Sun L, Chow LC, Frukhtbeyn SA, Bonevich JE. Preparation and properties of nanoparticles of calcium phosphates with various $\mathrm{Ca} / \mathrm{P}$ ratios. J Res Natl Inst Stand Technol. 2010;115(4):243.

25. Acharyulu SR, Gomathi T, Sudha PN. Physico-chemical characterization of cross linked chitosan-polyacrylonitrile. Scholar Res Libr. 2013; 5(2):354-363.

26. Soares J, Santos J, Chierice G, Cavalheiro E. Thermal behavior of alginic acid and its sodium salt. Eclética Quím. 2004;29(2):57-64.

27. Hirschhaeuser F, Menne H, Dittfeld C, West J, Mueller-Klieser W, Kunz-Schughart LA. Multicellular tumor spheroids: An underestimated tool is catching up again. J Biotechnol. 2010;148(1):3-15.

28. Llabot JM, Salman H, Milotti G, Bernkop-Schnurch A, Allemandi D, Manuel Irache J. Bioadhesive properties of poly(anhydride) nanoparticles coated with different molecular weights chitosan. J Microencapsul. 2011;28(5):455-463.

29. Joerger M, Huitema AD, van den Bongard DH, Schellens JH, Beijnen JH. Quantitative effect of gender, age, liver function, and body size on the population pharmacokinetics of paclitaxel in patients with solid tumors. Clin Cancer Res. 2006;12(7):2150-2157.

30. Gabizon A, Catane R, Uziely B, et al. Prolonged circulation time and enhanced accumulation in malignant exudates of doxorubicin encapsulated in polyethylene-glycol coated liposomes. Cancer Res. 1994;54(4): 987-992.

31. Aoudjit F, Vuori K. Integrin signaling inhibits paclitaxel-induced apoptosis in breast cancer cells. Oncogene. 2001;20(36):4995-5004.

32. Aas T, Børresen AL, Geisler S, et al. Specific P53 mutations are associated with de novo resistance to doxorubicin in breast cancer patients. Nat Med. 1996;2(7):811-814.

33. Kawakami H, Dosako S, Lonnerdal B. Iron uptake from transferrin and lactoferrin by rat intestinal brush-border membrane vesicles. Am J Physiol. 1990;258(4 pt 1):G535-G541.

34. Takayama Y, Takahashi H, Mizumachi K, Takezawa T. Low density lipoprotein receptor-related protein (LRP) is required for lactoferrinenhanced collagen gel contractile activity of human fibroblasts. J Biol Chem. 2003;278(24):22112-22118.

35. Rodgers GM 3rd, Becker PS, Blinder M, et al. Cancer- and chemotherapyinduced anemia. J Natl Compr Canc Netw. 2012;10(5):628-653.

36. Schwartz RN. Anemia in patients with cancer: Incidence, causes, impact, management, and use of treatment guidelines and protocols. Am J Health Syst Pharm. 2007;64:S5-S13.

37. Kanwar RK, Kanwar JR. Immunomodulatory lactoferrin in the regulation of apoptosis modulatory proteins in cancer. Protein Pept Lett. 2013; 20(4):450-458.

38. Spivak JL, Gascon P, Ludwig H. Anemia management in oncology and hematology. Oncologist. 2009;14:43-56. 


\section{Supplementary materials}

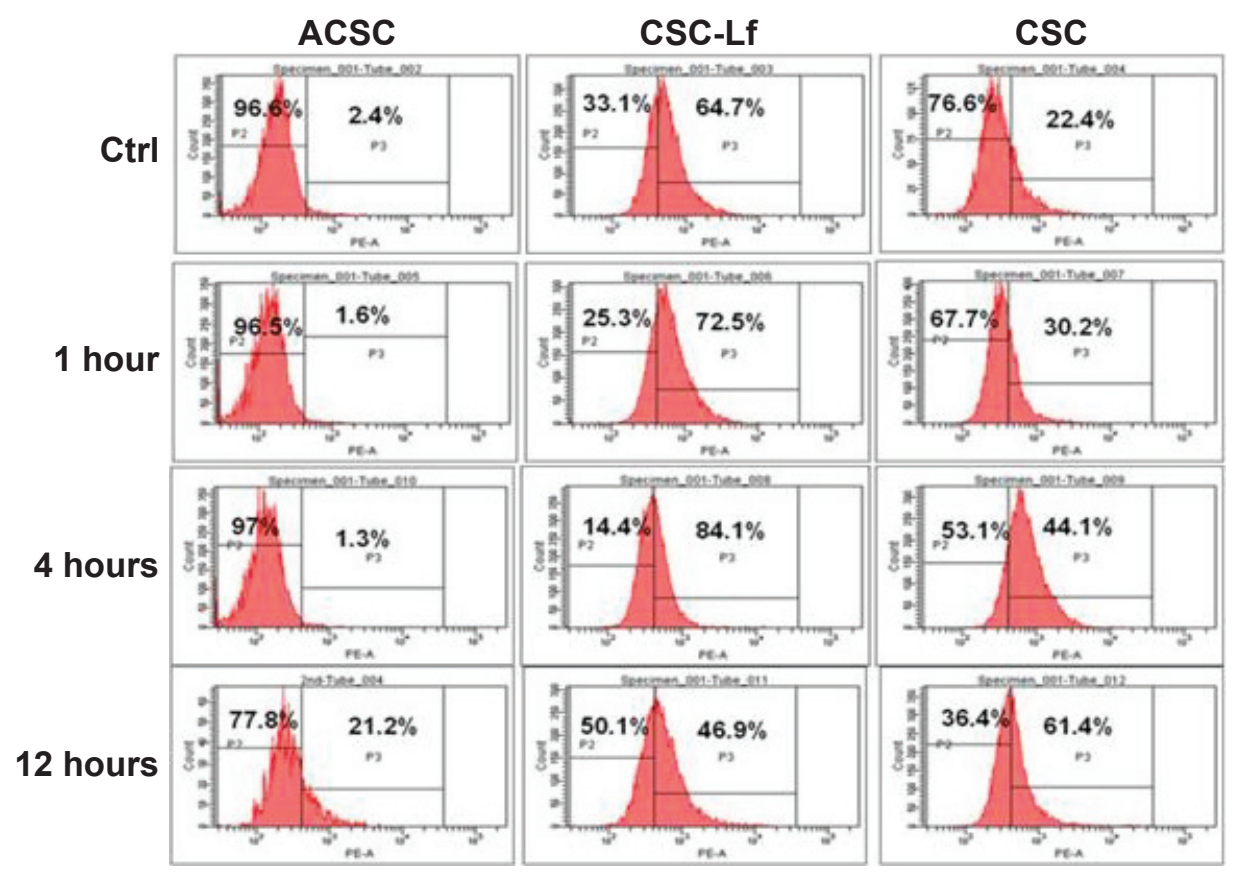

Figure SI Time dependent internalization of NCs.

Abbreviations: ACSC, alginate-enclosed chitosan-coated calcium phosphate; CSC, chitosan-coated calcium phosphate; Fe-bLf, iron-saturated bovine lactoferrin; NCs, nanocapsules/nanocarriers.

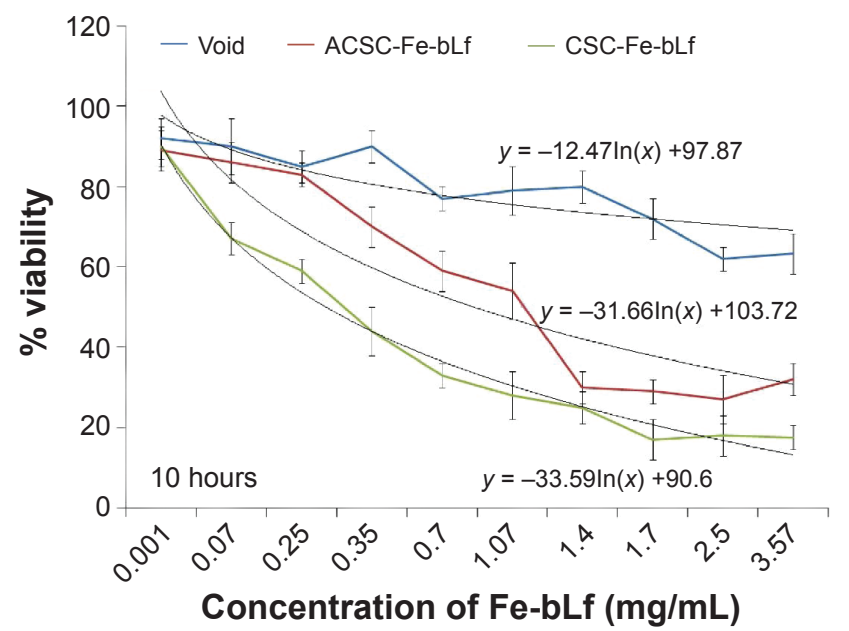

Figure S2 Determining the percentage viability in MDA-MB2-3I cells with NC treatments at $10 \mathrm{~h}$.

Abbreviations: ACSC, alginate-enclosed chitosan-coated calcium phosphate; CSC, chitosan-coated calcium phosphate; Fe-bLf, iron-saturated bovine lactoferrin; h, hours; NC, nanocapsule/nanocarrier.

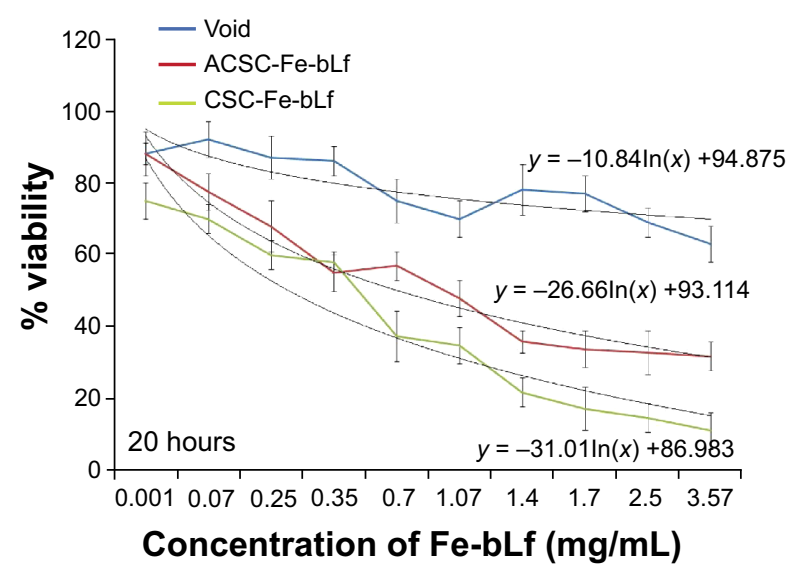

Figure S3 Determining the percentage viability in MDA-MB2-3I cells with NC treatments at $20 \mathrm{~h}$.

Abbreviations: ACSC, alginate-enclosed chitosan-coated calcium phosphate; CSC, chitosan-coated calcium phosphate; h, hours; Lf, lactoferrin; NC, nanocapsule/ nanocarrier. 
A

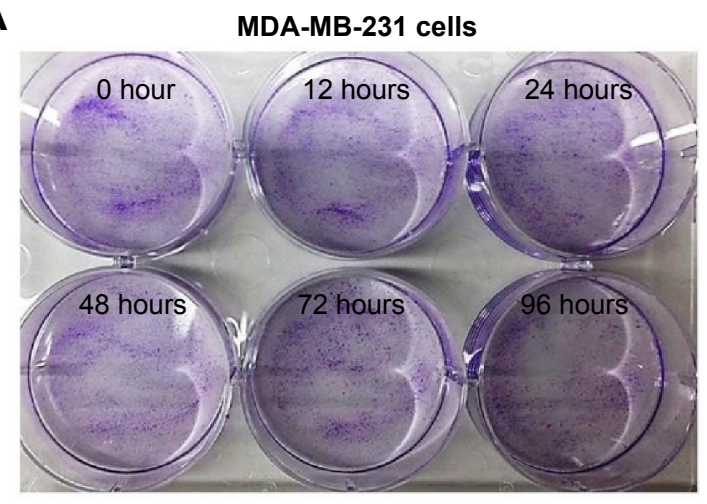

B

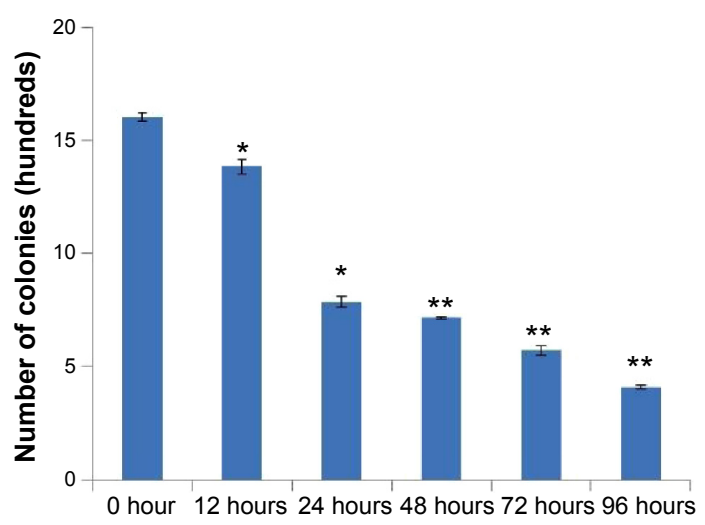

Figure S4 Determining the clonogenic potential of MDA-MB-23I with NC treatments.

Notes: (A) Clonogenic potential of MDA-MB-23I was performed. (B) It was revealed that the CSC-Fe-bLf NCs led to a significant reduction (*P $\leq 0.05)$ in I 2 and $24 \mathrm{~h}$ and a highly significant reduction $(* * P \leq 0.005)$ in 48,72 , and $96 \mathrm{~h}$.

Abbreviations: CSC, chitosan-coated calcium phosphate; Fe-bLf, iron-saturated bovine lactoferrin; h, hours; NCs, nanocapsules/nanocarriers.

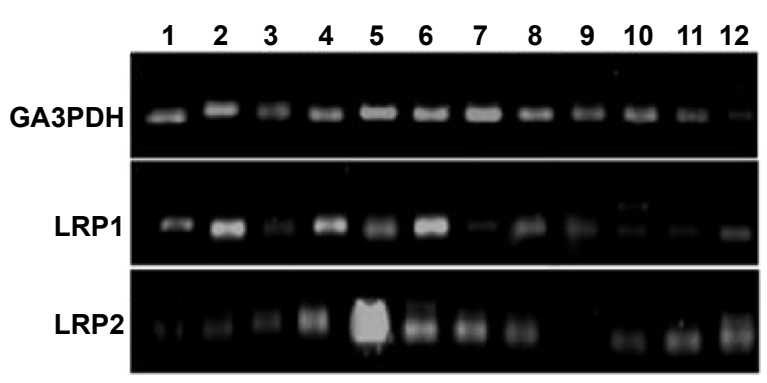

Figure S5 Agarose gel images of the Q-RT-PCR (quantitative real time polymerase chain reaction) products.

Abbreviation: LRP, low-density lipoprotein receptor.

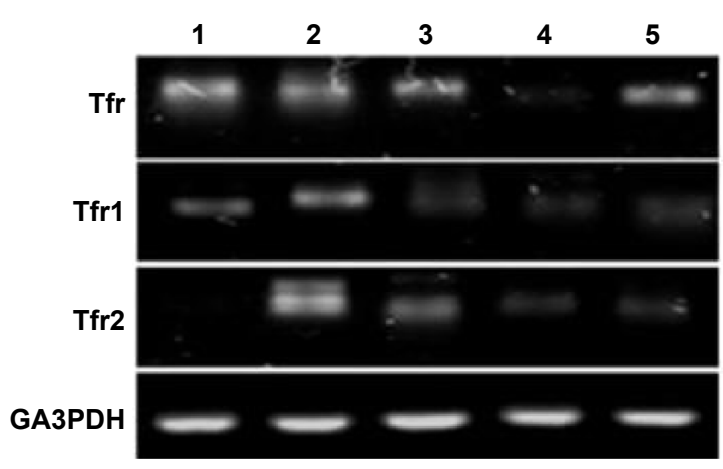

Figure S6 Agarose gel images of the Q-RT-PCR (quantitative real time polymerase chain reaction) of TfR and its isoforms.

Abbreviation: TfR, transferrin receptor.

Table SI Comparison of physicochemical and biological characters in CSC-Fe-bLf NCs and ACSC-Fe-bLf NCs

\begin{tabular}{lll}
\hline Characteristics & CSC-Fe-bLf NCs & ACSC-Fe-bLf NCs \\
\hline Size, $\mathrm{nm}$ & $205 \pm 15$ & $322 \pm 27.2$ \\
Zeta potential & -0.217 & -1.29 \\
Poly dispersity index & 0.073 & 0.084 \\
Encapsulating efficacy & $80 \%$ & - \\
Loading capacity & $25.8 \%$ & - \\
$\mathrm{IC}_{50}$ at $20 \mathrm{~h}, \mathrm{mg} / \mathrm{ml}$ & 1.192 & 1.62 \\
Internalization efficacy $\left(4 \times 10^{5} \mathrm{NCs}\right), \%$ & $86.6 \pm 2.25$ & $43 \pm 1.5$ \\
\hline
\end{tabular}

Note: Data shown in the Size and Internalization efficacy row as mean \pm SD.

Abbreviations: $\mathrm{IC}_{50}$, half maximal inhibitory concentration; ACSC, alginate-enclosed chitosan-coated calcium phosphate; CSC , chitosan-coated calcium phosphate; Fe-bLf, iron-saturated bovine lactoferrin; NCs, nanocapsules/nanocarriers.

International Journal of Nanomedicine

\section{Publish your work in this journal}

The International Journal of Nanomedicine is an international, peerreviewed journal focusing on the application of nanotechnology in diagnostics, therapeutics, and drug delivery systems throughout the biomedical field. This journal is indexed on PubMed Central, MedLine, CAS, SciSearch ${ }^{\circledR}$, Current Contents ${ }^{\circledR} /$ Clinical Medicine,

\section{Dovepress}

Journal Citation Reports/Science Edition, EMBase, Scopus and the Elsevier Bibliographic databases. The manuscript management system is completely online and includes a very quick and fair peer-review system, which is all easy to use. Visit http://www.dovepress.com/ testimonials.php to read real quotes from published authors. 